\title{
LA REGULACIÓN DEL “TESTAMENTO VITAL” EN ITALIA: ESTUDIO CRÍTICO DE LA LEY 219/2017
}

\author{
THE REGULATION OF THE "LIVING WILL" IN ITALY: \\ CRITICAL STUDY OF THE 219/2017 Act
}

\begin{abstract}
UGO ADAMO*
Recibido: 04/06/2018

Aceptado: 30/06/2018

SUMARIO: I. INTRODUCCIÓN. II. DEL VACÍO LEGAL A LA COMPLETA REGULACIÓN. III. LA NATURALEZA DE LAS "DISPOSICIONES” ANTICIPADAS DE TRATAMIENTO. REFLEXIONES SEMÁNTICAS. IV. LA VINCULACIÓN Y LA ACTUALIDAD DE LAS DISPOSICIONES ANTICIPADAS DE TRATAMIENTO. V. ARGUMENTOS PARA UNA INTERPRETACIÓN RESTRICTIVA DE LOS LÍMITES DEL CONTENIDO DE LAS DISPOSICIONES ANTICIPADAS DE TRATAMIENTO. EL ROL DEL MÉDICO. A) LOS CONTROLÍMITES DE OPERATIVIDAD DE LAS DISPOSICIONES ANTICIPADAS DE TRATAMIENTO. B) SOBRE LA OBJECIÓN DE CONCIENCIA. C) LA PLANIFICACIÓN COMPARTIDA DEL TRATAMIENTO. VI. LA NUTRICIÓN Y ALIMENTACIÓN ARTIFICIALES COMO TRATAMIENTO SANITARIO. VII. EL FIDUCIARIO COMO INSTRUMENTO DE FLEXIBILIZACIÓN Y DE TRÁMITE DE LA VOLUNTAD AJENA.VIII. LA SEDACIÓN PALIATIVA PROFUNDA CONTINUA Y SU NATURALEZA APLICATIVA. IX. REDACCIÓN DE LAS DISPOSICIONES ANTICIPADAS DE TRATAMIENTO. X. CONCLUSIONES.
\end{abstract}

SUMMARY: I. INTRODUCTION. II. FROM A LEGISLATIVE VACUUM TO A COMPLETE REGULATION. III. ADVANCE “PROVISIONS" TREATMENT'S NATURE. SEMANTIC REFLECTION. IV. ADVANCE PROVISIONS OF TREATMENT BINDINGNESS AND ACTUALITY V. TOPICS TO A CLOSED INTERPRETATION OF ADVANCE TREATMEANT PROVISIONS: LIMITS AND CONTENT. THE MD'S ROLE. A) OPERABILITY'S COUNTER-LIMITS OF ADVANCE TREATMENT PROVISIONS. B) ABOUT CONSCIENTIOUS OBJECTION. C) ADVANCE CARE PLANNING. VI. ARTIFICIAL NUTRITION AND FEEDING AS A SANITARY TREATMENT. VII. THE TRUSTEE AS AN INSTRUMENT OF FLEXIBILITY AND AS A MEANS OF WILLING. VIII. DEEP CONTINUOUS PALLIATIVE SEDATION AND ITS IMPLEMENTING NATURE. IX. EDITORIAL DIRECTIVES FOR A DRAFT OF ADVANCE PROVISIONS. X. CONCLUSIONS.

Resumen: Tras la reciente entrada en vigor de la ley estatal n. 219/2017, el legislador italiano ha finalmente llenado el vacío legal respecto a las disposiciones anticipadas de tratamiento. El presente ensayo afronta los trabajos doctrinales y las orientaciones jurisprudenciales en torno al proceso de fin de vida, a la luz de la nueva disciplina legislativa en materia. A una distancia de más de quince años de lo ocurrido en el sistema legal ibérico, en Italia el legislador opta por una disciplina permisiva en materia de "testamento vital". Después de un comentario sobre el texto legislativo, que destaca

\footnotetext{
* Doctor en Justicia Constitucional y Derechos Fundamentales, Universidad de Pisa. Investigador posdoctoral en Derecho Constitucional, Universidad ‘Magna Graecia’ de Catanzaro, Italia. ugo.adamo@unical.it.
}

https://dx.doi.org/10.17651/rej.n18.a1 
luces y sombras, en el trabajo se afirma que más allá de los aspectos críticos (interpretativos), todavía existentes, la ley se inserta completamente en el texto y contexto constitucional italiano y es completamente capaz de garantizar el habeas corpus de forma adecuada a la edad de la técnica.

Palabras clave: Testamento vital, disposiciones anticipadas de tratamiento, sedación paliativa, fin de vida, autodeterminación.

\begin{abstract}
Following the recent publication of the national Law n. 219/2017, legislator has finally filled the gap around the regulation on advance directive. The essay analyzes the contribution of doctrinal elaborations and the jurisprudential orientations around the end of life process, in the light of a new legislative discipline on the subject. After more than fifteen years from what occurred in the Spanish legal system, the Italian legislator opts for a permissive discipline on the topic of living will. After commenting on the legislative text, by pointing out both pros and cons, the essay claims that, even though some critical (interpretative) issues are present, the law is fully consistent with the legislative and constitutional Italian frameworks and wholly fits to safeguard habeas corpus in a way genuinely appropriate to new technology.
\end{abstract}

Keywords: Living will, advance directives of treatment, palliative sedation, end of life, self-determination

\title{
I. INTRODUCCIÓN
}

El desarrollo y la aplicación de la tecnología y de la investigación médica intervienen desde hace algunos decenios en modo cada vez más decisivo en todas las fases de la vida y de la muerte - previamente asignadas a los tiempos de la naturaleza -, controlándolas, influenciándolas y planteando (en algunos casos dramáticamente) cuestiones controvertidas que necesitan ser encaradas y resueltas.

Una medicina tecnocrática (en modo más general, la medicalización de la vida) ${ }^{1}$, incidiendo sobre el cuerpo humano, influye sobre la naturaleza del mismo, provocando que la persona ya no logre ser (al menos exclusivamente y en cada circunstancia) "dueña" ${ }^{2}$ de sí misma, de lo que se deduce que la vida del hombre se ha convertido en uno de los «oggetti della tecnica» ${ }^{3}$.

\footnotetext{
${ }^{1}$ ILLICH, I., Nemesi medica. L'espropriazione della salute. La paradossale nocività di un sistema medico che non conosce limiti, Red, Milán, 2005, p. 19.

${ }^{2} \mathrm{Al}$ respecto escribe Rodotà, S., «[d] i chi è il corpo? Della persona interessata, della sua cerchia familiare, di un Dio che l'ha donato, di una natura che lo vuole inviolabile, di un potere sociale che in
} 
El moderno saber médico y bio-tecnológico no se limita a prolongar la vida pero influye, sobre todo, en el modo en el que se vive y se experimenta la enfermedad (rectius: la vida corpórea) hasta los últimos momentos de la existencia, inclusive - pero no exclusivamente- en las fases terminales. Y es justo esta "injerencia” técnica que ha abierto nuevos tiempos y espacios de elección sobre los cuales, hasta entonces, nunca se había tenido la necesidad de interrogarse ni de decidir.

El conocimiento y la posibilidad de acceder a una técnica, por otra parte, no significan que ésta tenga que ser utilizada obligatoriamente ${ }^{4}$. Es necesario destacar, en efecto, que junto a los conocimientos que permiten un amplio abanico de oportunidades se ubican también algunos obstáculos que limitan las elecciones individuales y condicionan el devenir somatopsíquico, así como sucede para el fin de vida en el momento en que los conocimientos técnicos puedan comportar la dilatación de la vida biológica más allá de cuanto el sujeto quiera o haya pensado que fuera posible, dejando atrás la imagen de "la parca”, que llega sin que nadie la espere y que no es (ni puede ser) frenada por nadie ${ }^{5}$.

Esta nueva realidad atravesada por la ética, la ciencia, la filosofía, el psicoanálisis, el derecho y la religión - que conlleva el planteamiento de determinadas preguntas y determinadas respuestas - es (debe ser) obligatoriamente gobernada por una decisión común denominada regulación legislativa, y - considerando el ordenamiento constitucional italiano - la reciente Ley n. 219/2017 es un claro ejemplo de la misma.

Nos encontramos ante un proceso de fin de vida que constituye no un momento, un instante puntual en el tiempo ${ }^{6}$ o un hecho inevitable, sino más bien una fase (tal vez larga) no limitada por un final inminente ${ }^{7}$. "Fin de vida" constituye, precisamente, una expresión que indica - y en tal sentido es utilizada - una fase y no un instante, como

mille modi se ne impadronisce, di un medico o di un magistrato che ne stabiliscono il destino?» en La vita e le regole. Tra diritto e non diritto, Feltrinelli, Milán, 2006, p. 73.

${ }^{3}$ JoNAS, H., Il principio responsabilità. Un'etica per la civiltà tecnologica, Einaudi, Turín, 2002, p. 24; TRIPODINA, C., Il diritto nell'età della tecnica. Il caso dell'eutanasia, Jovene, Nápoles, 2004, pp. 1 y ss. Sobre tal punto, si se quiere, se remite a ADAMO, U., Costituzione e fine vita. Disposizioni anticipate di trattamento ed eutanasia, Cedam, Wolters Kluwer, Milano, 2018.

${ }^{4}$ Sobre todo si se considera que la técnica «non tende ad uno scopo, non promuove un senso, non apre scenari di salvezza, non redime, non svela la verità: la tecnica funziona», GALIMBERTI, U., Psiche e techne. L'uomo nell'età della tecnica, Feltrinelli, Milán, 1999, p. 33; HABERMAS, J., Il futuro della natura umana. I rischi di una genetica liberale, Einaudi, Turín, 2002, pp. 26 y ss.; MORRONE, A., "Ubi scientia ibi iura”, Consulta online, pp. 1 y ss.

${ }^{5}$ La muerte era imprevista, prematura, impostergable, breve: adjetivos empleados por MoRI, M., "Un' 'analisi bioetica' dell'attuale disputa sul testamento biologico come estensione del consenso informato", Notizie Politeia, n. 102/2011, p. 64. La muerte sigue siendo un hecho "natural" (sigue afectando a todos) pero cada vez más pierde la connotación de "naturalidad" (fenómeno fuera del control de los seres humanos), V. Borsellino, P., "Il rifiuto delle cure e dei trattamenti medici vitali", en Cagnazzo, A., (coord.), Trattato di diritto e bioetica, Edizioni Scientifiche Italiane, Nápoles, 2017, p. 184, nt. 8.

${ }^{6}$ El evento de la muerte no es más un hecho: Pizzetti, F.G., Alle frontiere della vita: il testamento biologico tra valori costituzionali e promozione della persona, Giuffrè, Milán, 2008, p. 375.

${ }^{7}$ Por lo tanto, es en esta acepción que se emplea la expresión "fin de vida", en modo incluso atecnico, dado que las decisiones sobre el proprio cuerpo - como se verá en modo más profundo más adelante pueden ser tomadas también por personas grave e irreversiblemente enfermas y no por eso en "fin de vida". 
puede ser en el caso de la muerte ${ }^{8}$. Esto significa - inclusive y en consecuencia - que en el proceso de fin de vida pueden confluir múltiples situaciones que exigen diferentes intervenciones y la toma de decisiones ante variadas circunstancias, las cuales, sin embargo, a menudo se encuentran aunadas por una misma situación, o sea, aquella por la cual cuando se muere (ya) no se muere solo, sino que se muere casi siempre en un contexto hospitalizado en el que el paciente mantiene relaciones con la comunidad sanitaria y no sanitaria y, por lo tanto, con una comunidad que en algún modo le es familiar.

\section{DEL VACÍO LEGAL A SU REGULACIÓN}

A partir de los años '80 del siglo pasado se ha comenzado a discutirse, más que todo en los países anglosajones, sobre el "testamento vital”. En Italia sólo últimamente, después de 40 años $^{9}$, se ha elaborado una disciplina normativa sobre lo que en el panorama comparado o, de todos modos, en el ámbito de la literatura, se conoce bajo el nombre de "living will" o de "testamento vital". Uno de los primeros documentos publicados en Italia respecto a esta temática fue el texto redactado por el Comité Nacional de Bioética, el cual opta por el empleo de la expresión "declaración anticipada de tratamiento" $(\mathrm{DAT})^{10}$ y define tal instrumento como un documento en el cual «una persona, dotata di piena capacità, esprime la sua volontà circa i trattamenti ai quali desidera o non desidera essere sottoposta nel caso in cui, nel decorso di una malattia o a causa di traumi improvvisi non fosse in grado di esprimere il proprio consenso o il proprio dissenso informato» ${ }^{11}$.

Aun no siendo una novedad, se verifica un nuevo interés en la materia gracias a la reciente publicación de la Ley n. 219, de 22 de diciembre de 2017, respecto a las normas sobre el consentimiento informado y a las decisiones anticipadas de tratamiento ${ }^{12}$.

Luego de haberse verificado una variación en el escenario político (de la mayoría gubernamental) y en la "sensibilidad" (laica) del nuevo Parlamento, el Legislador, tras algunos intentos fallidos de encuadrar jurídicamente la "declaración” anticipada de tratamiento ${ }^{13}$, parece que haya decidido positivizar los principios ya consolidados en

\footnotetext{
${ }^{8}$ V. PATTI, S., “La fine della vita e la dignità della morte”, Famiglia, persone, successioni, n. 5/2006, p. 390.

${ }^{9}$ V. TRIPODINA, C., "Tentammo un giorno di trovare un modus moriendi che non fosse il suicidio né la sopravvivenza. Note a margine della legge italiana sul fine vita (l. n. 219/2017)”, Forum di Quaderni costituzionali, n. 3/2017, p. 1.

${ }^{10}$ En el texto se empleará el acrónimo DAT en referencia a las disposiciones anticipadas de tratamiento (tal como lo hace la Ley 219/2017) y no la expresión 'testamento vital' o 'biológico', aun si estas últimas expresiones resultan más conocidas al lector español. Las razones del uso del acrónimo DAT serán especificadas infra en el párrafo III.

${ }^{11}$ Resolución del 18 de diciembre del 2003 Dichiarazioni anticipate di trattamento.

${ }^{12}$ El texto ha sido aprobado el 14 de diciembre del 2017 con 180 votos favorables, 71 contrarios y 6 abstenciones. Sobre tal novedad legislativa en materia véase CUPELLI, C., "Libertà di autodeterminazione terapeutica e disposizioni anticipate di trattamento: i risvolti penalistici”, www.dirittopenalecontemporaneo.it, n. 12/2017, pp. 123 y ss.

${ }^{13}$ Respecto al pasado reciente, hay que hacer mención al proyecto de ley Disposizioni in materia di alleanza terapéutica, di consenso informato e di dichiarazioni anticipate, que tras la aprobación en el
} 
materia jurisprudencial (administrativa, constitucional y europea) en lo que respecta tanto al consentimiento informado como al consenso de vinculación de las expresiones de voluntad expresadas "de hoy para mañana”.

El bagaje jurisprudencial es amplio pero continúa, gracias a su propia naturaleza, siendo reelaborado en base a los “casos de la vida”. Estos "casos de la vida” frecuentemente implican la prevalencia de un tipo de decisión respecto a otra, la cual no se toma siempre en modo coherente con la visión general del instituto ${ }^{14}$.

La necesidad de una certeza más sólida de parte del derecho y, en consecuencia, la disminución de la cantidad de recursos al juez se configuran como dos pilares del intento de transponer en un plano legislativo - a través de la formulación de reglas certeras - los principios (no tan imprecisos) presentes en el ordenamiento. De todos modos, si bien ésta sea la intención del Legislador, será necesario evaluar si éste ha actuado basándose sobre el ya existente «diritto dei principi» o si, por el contrario, está yendo hacia una «nuova legge» ${ }^{15}$.

El derecho de principios (incluso jurisprudenciales) nos ilustra un cuadro bastante completo y disciplinado, capaz de tomar forma basándose en casos concretos. La presencia de principios (constitucionales, convencionales e internacionales) ha dado como resultado que la falta de una ley específica no haya impedido a las jurisdicciones competentes de responder a las solicitudes de justicia provenientes de personas cuyos casos (humanos y de salud) pudieran ser englobados en la amplia y poliédrica materia del fin de vida.

En el presente contexto histórico que desde hace algunos decenios está delineado por el avance tecnológico, la salud ha adoptado una nueva dimensión que ha dejado de coincidir con la simple ausencia de enfermedad y que, en modo mucho más amplio, entra en sintonía con la autopercepción que cada uno tiene de sí mismo, al interno de la experiencia concreta que conduce hacia los demás ("vida biográfica”). Es así que el principio del consentimiento informado encuentra fundamento en los arts. 2, 13 y 32 de la Constitución italiana ${ }^{16}$. Tal principio es condicionante del accionar del médico, quien no puede aplicarlo sin que el paciente lo sepa (ni siquiera si actuara en el supuesto interés de éste). Al paciente se le reconoce la facultad de «rifiutare la terapia e di decidere consapevolmente di interromperla, in tutte le fasi della vita, anche in quella terminale» ${ }^{17}$ expresando su consentimiento libre, informado y conciente.

Claramente, si sobre el paciente se llevara a cabo un tratamiento que diera resultados inútiles, ineficaces y, por lo tanto, no funcionales a la recuperación del mismo, se incurriría en una invasión de la esfera personal que, además, sobrepasaría los límites de

Senado y la sucesiva modificación (el 12 julio 2011) de la Cámara (AC. 2350) no pudo ser aprobado antes de que concluyera la XVI Legislatura en el 14 marzo 2013.

${ }^{14}$ PizzetTi, F. G., "Considerazioni a margine del "caso Piludu” fra princìpi costituzionali e pronunce giurisprudenziali in materia di rifiuto di trattamenti sanitari salvavita”, Rivista di BioDiritto, n. 1/2017, pp. 219-231.

${ }^{15}$ ZATTI, P., “Salute, vita, morte: diritto per principi o nuova legge”, Quotidiano sanità, p. 1.

${ }^{16}$ SCC n. 438/2008. Incluso el Tribunal Constitucional de España ha tenido modo de interrogarse sobre la naturaleza del derecho del consentimiento informado; la decisión a la que urge hacer referencia es la STC 37/2011.

${ }^{17}$ No pudiéndose afirmar «che il diritto alla autodeterminazione terapeutica del paziente incontri un limite allorché da esso consegua il sacrificio del bene della vita», en Cas., sec. civ., sent. n. 21748/2007, punto 6.1 de Motivazioni in diritto. 
la asistencia y de la buena práctica médica. Dicho tratamiento no puede ser puesto en marcha en ausencia del consentimiento informado ni tampoco si no fuera proporcional a la exigencia de la situación de paciente. Si la urgencia ante un tratamiento (y siempre en el caso que no se tengan noticias de la DAT) comporta una intervención urgente que resulte beneficiosa para la salud del paciente, una vez superada la urgencia derivada del estado de necesidad, se restablece el dualismo de los sujetos involucrados en el proceso de elaboración de la decisión médica, o sea, entre el médico que debe informar el diagnóstico, el pronóstico y las posibilidades terapéuticas, y el paciente podrá aceptar o rechazar los tratamientos propuestos. Es así que en el respeto de la autodeterminación del paciente, incluidos quienes no fueran capaces de manifestar su propia voluntad (por encontrarse en un estado de total incapacidad y que, además, no hubieran indicado, cuando estaban en pleno uso de sus propias facultades, los tratamientos sanitarios que habrían querido o no habrían querido recibir en el caso de pérdida de la conciencia), existe la posibilidad de que ésta sea reconstruida a partir de sus expresiones de deseo y voluntad precedentes al estado de imposibilidad en el que se encontrara. "Il valore primario ed assoluto dei diritti coinvolti esige una loro immediata tutela ed impone al giudice una delicata opera di ricostruzione della regola di giudizio nel quadro dei principi costituzionali», también gracias a la intervención del representante legal, quien debe actuar "nell'esclusivo interesse dell'incapace» ${ }^{18}$. Existe, por lo tanto, el derecho de decidir "ahora para entonces", considerando una propia eventual incapacidad.

Hasta aquí se han expuesto algunos casos ya presentes en el ordenamiento jurídico que han exigido la positivación a través de una ley capaz de garantizar que la autodeterminación de las personas en estado de incosciencia no quede relegada al altar sagrado de la petitio principii. Se trata de llevar la atención al hecho que una intervención legislativa ${ }^{19}$ (o sea, la producción de un acto-fuente primario) conlleva también la posibilidad de que la Corte constitucional competente se exprese sobre la conformidad o no conformidad de la normativa elaborada a la Constitución y que, por lo tanto, se ponga en marcha un diálogo con el Legislador con vistas a elevar lo más posible el nivel de tutela en el ámbito del derecho a la salud, en sentido amplio ${ }^{20}$.

Tal como se ha señalado, la voluntad político-legislativa de elaborar una disciplina ad hoc parece ser el resultado de la persistente ausencia de una normativa respecto a la posibilidad de todo sujeto de hacer valer sus propias determinaciones vinculantes (aquellas que, más correctamente, deberían haberse denominado "directivas", véase el punto infra) ${ }^{21}$ cuando, encontrándose en pleno uso de sus facultades mentales (e incluso

\footnotetext{
${ }^{18}$ Así, también, Cas. civ., sent. n. 21748/2007.

${ }^{19}$ Que claramente no puede «perder de vista algunos elementos fundamentales suceptibles de delimitar el perímetro ideal en el cual colocar una buena ley en materia», en BORSELLINO, P., "La sfida di una buona legge in materia di consenso informato e di volontà anticipate sulle cure”, BioLaw Journal - Rivista di BioDiritto, 2/2014, p. 94.

${ }^{20}$ En esta perspectiva, aunque en un contexto absolutamente diferente (práctica eutanásica en Canadá), Casonato, C., y Tomasi, M., "Constitutional Dialogues in Canada. Corte Suprema e Parlamento sulle questioni di fine vita”, en Murgia, C., (coord.), Scritti in onore di Sara Volterra, Giappichelli, Turín, 2017, pp. 191 y ss.

${ }^{21}$ V. CASONATO, C., "Le direttive anticipate di trattamento: un fenomeno paradigmatico dei problemi del biodiritto”, en CECCHERINI, E., y GROPPI, T., (coords.), Bioetica, Edizioni Scientifiche Italiane, Nápoles, 2010; AZZALINI, M., "Le disposizioni anticipate del paziente: prospettiva civilistica”, en CANESTRARI, S., y Ferrando, G., y Mazzoni, C. M., y RodotÀ, S., y ZATTI, P., (coords.), Trattato di biodiritto, Il governo
} 
aunque no lo hiciera como paciente en dicho momento), quisiera decidir libremente ${ }^{22}$ sobre futuros eventuales tratamientos sanitarios sobre los cuales no pudiera decidir en un momento posterior, manifestando anticipadamente su voluntad a través de la redacción de un documento a tal efecto previsto por ley.

El panorama en Italia continuaba a sufrir de esta laguna legislativa ${ }^{23}$ parcialmente colmada por la jurisprudencia ${ }^{24}$ - o sea, por la posibilidad de constatar determinados tipos de condiciones en sede procesual que podían dar lugar a la interrupción de los tratamientos (como en el caso del estado vegetativo permanente), autorizando la reconstrucción de la voluntad y, en consecuencia, el eventual cese de los tratamientos de sostén vital ${ }^{25}$, o asignando a un tercero de la facultad de decidir por el beneficiario - y (colmada aunque con eficacia limitada) por algunas fuentes internacionales ${ }^{26} \mathrm{y}$ deontológicas, que en diferentes modos prevén el deber de tomar en consideración las directivas anticipadas.

No se estaba, por lo tanto, delante a un completa laguna jurídica sobre las “directivas” anticipadas de tratamiento ${ }^{27}$, lo que de por sí hubiese bastado para no hacer necesaria (tal vez) la producción de una normativa legislativa. ¿¿Lo mismo podría sostenerse

del corpo, Giuffrè, Milán, 2010, p. 1935; AgOSTA, S., Bioetica e Costituzione. II. Le scelte esistenziali di fine-vita, Giuffrè, Milán, 2012, p. 127.

${ }^{22}$ Se refiere a una «opportunità» puesta a disposición de las personas. RoDOTÀ, S., La vita e le regole, cit., p. 259.

${ }^{23}$ Incluso luego de la "invitación” (o advertencia) realizada por la misma Corte constitucional que resolviendo (declarada la inexistencia) un conflicto de atribuciones señalado por las Cámaras contra una decisión de la Corte de Casación, la cual fue “acusada” de haber pronunciado una decisión en ausencia de una ley - ha expresado, haciendo uso de palabras claras y directas, que «il Parlamento può in qualsiasi momento adottare una specifica normativa della materia, fondata su adeguati punti di equilibrio fra $i$ fondamentali beni costituzionali coinvolti» (OCC n. 334/2008); en doctrina, al menos BIN, R., "Se non sale in cielo, non sarà forse un raglio d'asino?”, Forum di Quaderni costituzionali, p. 3. Más recientemente, la misma Corte ha recordado que el Legislador estatal posee la competencia de regular en materia de DAT en cuanto «[d]ata la sua incidenza su aspetti essenziali della identità e integrità della persona, una normativa - necessariamente articolata - in tema di disposizioni di volontà relative ai trattamenti sanitari nella fase terminale della vita [...] necessita di uniformità di trattamento sul territorio nazionale, per ragioni imperative di eguaglianza»; V. SCC n. 262/2016, punto 5.4. F. J.

${ }^{24}$ El legislador ha, en realidad, delegado las cuestiones más controversiales a los jueces (quienes se han encontrado siempre delante a un parámetro bastante amplio). La disciplina legislativa de las materias inherentes al fin de vida es sin duda alguna útil, incluso para garantizar un idéntico tratamiento en cualquier parte del territorio estatal independientemente de la ausencia, en nuestro ordenamiento, del principio stare decisis. Véase MorelLI, A., “I diritti senza legge”, Consulta online, n. 1/2015, pp. 1 y ss.; TRIPODINA, C., "Nascere e morire tra diritto politico e diritto giurisprudenziale”, en CAVINO, M., y ID. (coords.), La tutela dei diritti fondamentali tra diritto politico e diritto giurisprudenziale: "casi difficili" alla prova, Milán, 2012, p. 80; TONDI DELlA MuRA, V., "Il «caso Englaro», ovvero: dell' «invincibilità» della regola «perfetta»”, en D’ALOIA, A., (coords.), Il diritto e la vita. Un dialogo italo-spagnolo su aborto ed eutanasia, Jovene, Nápoles, 2011, pp. 81 y ss.; DoNINI, M., "La necessità di diritti infelici. Il diritto di morire come limite all’intervento penale”, Rivista italiana di Medicina Legale, n. 2/2016, p. 571. ${ }^{25}$ V. ex multis, Cas. civ., sec. I, 16 de octubre del 2007, sent. n. 21748; Cons. Est., sec. III, del 2 de septiembre del 2014, n. 4460.

${ }^{26}$ El Convenio para la protección de los Derechos Humanos y la dignidad del ser humano con respecto a las aplicaciones de la Biología y la Medicina (Convenio de Oviedo, 1997) que en el artículo 9 afirma: «i desideri precedentemente espressi a proposito di un intervento medico da parte di un paziente che, al momento dell'intervento, non è in grado di esprimere la sua volontà saranno tenuti in considerazione».

${ }^{27}$ La laguna legislativa, en cambio, fue confirmada por la Corte costituzionale en la ordenanza n. $334 / 2008$. 
también respecto a la posibilidad de que el órgano constitucional representativo de la soberanía nacional haya expresado una decisión en materia de disposiciones anticipadas de tratamiento? Consideramos que la respuesta a esta pregunta es negativa.

Para dar una mayor certidumbre al derecho es necesaria una intervención legislativa que en dicha materia parece todavía carente. Es exactamente la exigencia de garantizar una mayor certeza jurídica la que reclama la conformación de una disciplina sobre las disposiciones anticipadas de tratamiento a través de una legislación estatal, en modo de limitar las distintas "iniciativas" locales ${ }^{28}$ y las posibles diferentes interpretaciones de parte de las diferentes autoridades judiciales ${ }^{29}$, dado que en un sistema que no es (y continua no siendo) de common law, no se aplica el vínculo del precedente ${ }^{30}$.

Es cierto que en el ordenamiento existe el derecho a decidir sobre los propios tratamientos como también existe el derecho a decidirlo anticipadamente para hacer valer el proprio deseo en el caso de que una persona no estuviera en condiciones de expresarse dado un eventual estado de incapacidad, pero no es posible afirmar lo mismo respecto a la modalidad de ejercicio del derecho ${ }^{31} \mathrm{y}$, por lo tanto, sobre su garantía ${ }^{32}$. De hecho, sólo la disciplina legal respecto a las directivas anticipadas es capaz de resolver

\footnotetext{
${ }^{28}$ Es sabido, de hecho, que varios municipios han establecido desde hace tiempo un registro de las disposiciones anticipadas de tratamiento. Por ejemplo, la reciente Ley regional del Friuli-Venecia Julia del 2015, n. 16, Istituzione del registro regionale per le libere dichiarazioni anticipate di trattamento sanitario (DAT) e disposizioni per favorire la raccolta delle volontà di donazione degli organi e dei tessuti, fue declarada inconstitucional por vicio de incompetencia con SCC n. 262/2016. V. PICIOCCHI, C., "Dichiarazioni anticipate di trattamento: dare forma al vuoto in attesa di una legge”, Rivista Aic, 2/2016, pp. 13 y ss.; MAGNANI, C., "Sul testamento biologico altro scontro tra Stato e Regioni. Il Titolo V fa male alla salute?”, Forum di Quaderni costituzionali, pp. 1 y ss.

${ }^{29}$ MORELLI, A., Op. cit., pp. 17 y ss. El A. subraya las diferencias que subsisten entre las "respuestas" al interno de las disponibilidades (consideradas sus diferentes naturalezas) del legislador y del juez; de hecho, sólo el segundo está limitado por el principio de la pregunta tal como lo define el thema decidendum. Además (p. 29) la inexistencia de una ley general y abstracta que remite al juez la decisión sobre el caso concreto, produce una disparidad (violación del principio de igualdad) entre quien tiene la posibilidad y los recursos para acceder a los instrumentos de protección y quien, por no poseerlos, queda exlcuido del derecho no positivamente reconocido.

${ }^{30}$ ResCIGNO, G.U., "Dal diritto di rifiutare un determinato trattamento sanitario secondo l'art. 32, co. 2, Cost., al principio di autodeterminazione intorno alla propria vita”, Diritto Pubblico, n. 1/2008, pp. 85112; AGOSTA, S., "Della guerra tra poteri che si accende quando una vita si spegne: a margine della proposta di legge in tema di dichiarazioni anticipate di trattamento", STAIANO, S., "Legiferare per dilemmi sulla fine della vita: funzione del diritto e moralità del legislatore”, ambos en D’AlOIA, A., (coord.), Il diritto alla fine della vita. Principi, decisioni, casi, Editoriale Scientifica Italiana, Nápoles, 2012, y respectivamente en pp. 369-392 y pp. 393-406.

${ }^{31}$ CARLASSARE, L., "La Costituzione, la libertà e la vita", Astrid, 6, cursivas del A. Para el A., (V. también ID., "Dignità della persona e libertà di cura”, Scritti in onore di Franco Modugno, I, Editoriale Scientifica, Nápoles, 2011, pp. 567 y ss.) de hecho, se debería hablar de la oportunidad que representaría una normativa que resolviera las incertezas causadas por los casos poco concretos (realizada sobre todo para respaldar a los operadores médicos en caso de eventuales responsabilidades resarcitorias) y no tanto de su necesidad, considerando la vigencia del art. 32 de la Constitución que afirma que «il diritto di ogni persona a dichiarare anticipatamente la propria volontà in materia di cure al fine di farla valere nel proprio futuro qualora non sia più in grado di esprimerla», 3. Al respecto, v. PuZzo, F., "Progresso biotecnologico, personalismo costituzionale e diritto alla vita”, Forum di Quaderni costituzionali, pp. 12 y ss. ${ }^{32}$ PIOGgiA, A., "Consenso informato e rifiuto di cure: dal riconoscimento alla soddisfazione del diritto. A proposito della sentenza Tar Lombardia 214 del 2009”, Astrid, p. 5; GRANDI, F., "Questioni di coscienza del pubblico potere: risvolti costituzionali dell'infedeltà/inosservanza dell'Amministrazione”, Giurisprudenza costituzionale, n. 3/2016, pp. 1289 y ss.
} 
las múltiples problemáticas que podrían presentarse y, sin ella, muy probablemente, será tarea de un juez (exclusivamente en un contexto de procedimiento judiciario) la constatación, por ejemplo, de la voluntad de la persona incapacitada así como la resolución de las problemáticas resultantes de la reconstrucción de la misma. Tampoco será menos simple la realización de dicha comprobación con la intervención de un tutor $^{33}$. Mas la decisión será tomada por un juez y no por el paciente a través de una intervención a tal efecto predispuesta por el legislador, quien en cambio debería - sobre todo en estas "nuevas" materias - reivindicar su propio rol de representación de los intereses y derechos de las personas (incluso aquéllos distintos y opuestos) y de predominio $^{34}$ en relación al derecho jurisprudencial. Si se hubiese prolongado tal inversión de predominio, se habría establecido un vulnus todavía más insoportable para la tutela de los derechos fundamentales que exige, cada vez con mayor conciencia, un reconocimiento significativo.

Por lo tanto, no se verifica un acuerdo con la influyente doctrina ${ }^{35}$ bajo la que actúan aquellos jueces que, tras haber citado la jurisprudencia de la Corte de Casación sobre el "asunto Englaro" y la jurisprudencia de la Corte constitucional sobre el consentimiento informado, afirman que es de «difficile confutazione la conclusione dell'assoluta superfluità di un intervento del Legislatore volto ad introdurre e disciplinare il c.d. testamento biologico» ${ }^{36}$. Este argumento ha sido desarrollado posteriormente a la luz de una interpretación "extensiva” del contenido de la administración de sostenimiento, que tiende a superponer tal asunto a la cuestión sobre las disposiciones anticipadas de tratamiento y que en la doctrina fue acuñado bajo il neologismo «testamento di sostegno» ${ }^{37}$. Pero luego intervino, precisamente, la Ley n. 219 del 22 de diciembre de 2017.

\section{LA NATURALEZA DE LAS “DISPOSICIONES” ANTICIPADAS DE TRATAMIENTO. REFLEXIONES SEMÁNTICAS}

¿Cuál es el grado de vinculación de las DAT? Además, ¿qué contenido pueden tener? ¿Quién las pueden redactar?

Es necesario dar una respuesta a las tres preguntas a partir de la normativa recientemente publicada, que habla de "disposiciones" anticipadas de tratamiento ${ }^{38}$, o

\footnotetext{
${ }^{33}$ VIGANÒ, F., “L'interruzione dell'alimentazione e dell’idratazione artificiali nei confronti dei pazienti in stato vegetativo permanente: la prospettiva penalistica”, Forum di Quaderni costituzionali, p. 19.

${ }^{34}$ TRIPODINA, C., "Il “diritto” a procreare artificialmente in Italia: una storia emblematica, tra legislatore, giudici e Corti”, Rivista di BioDiritto, n. 2/2014, p. 85.

${ }^{35}$ RoDOTÀ, S., "L’appello sospetto alla Legge”, Il Manifesto, 23 de diciembre del 2006.

36 Trib. de Módena, decr. del 13 de mayo del 2008. En el mismo sentido también el Trib. de Prato, decr. del 8 de abril del 2009.

${ }^{37}$ PAGLIANI, G., “Trattamenti sanitari, fine vita e amministrazione di sostegno”, Giurisprudenza di merito, n. 7-8/2009, 1794; COSCIONI, G., "L’amministrazione di sostegno rende superfluo il testamento biologico", Questioni di diritto e famiglia, 2008.

${ }^{38}$ Contrariamente a la situación que se ha verificado en Italia (Vid; nt. 28 y 128), en España todas las CCAA han dado como resultado una legislación que regula el documento, el cual provee diversas (incluso muchas) denominaciones entre las cuales aparece, además de la ya propuesta fórmula de las instrucciones previas (presente en la ley estatal) - Asturias: decreto 4/2008, del 23 de enero, "de Organización y Funcionamiento del Registro del Principado de Asturias de Instrucciones Previas en el ámbito sanitario”.
} 
sea, de aquellas decisiones orientadas «al futuro in previsione di situazioni ipotetiche [y que] esigono una mediazione interpretativa, di attualizzazione e di concretizzazione, volta al fine del miglior rispetto delle convinzioni, delle preferenze e della volontà del dichiarante nella situazione data, e affidata alla collaborazione tra il medico e un

Castilla y León: art. 30 “Instrucciones previas” della 1. n. 8/2003 “sobre derechos y deberes de las personas en relación con la salud”. La Rioja: l. n. 9/2005 "reguladora del documento de instrucciones previas en el ámbito de la sanidad”. Comunidad de Madrid: l. n. 3/2005 "por la que se regula el ejercicio del derecho a formular instrucciones previas en el ámbito sanitario y se crea el registro correspondiente”. Murcia: decreto 80/2005 "por el que se aprueba el reglamento de instrucciones previas y su registro" -, aquellas de voluntades anticipadas (Cataluña: l. n. 21/2000, del 29 diciembre Sobre los derechos de información concernientes a la salud y a la autonomía del paciente, y la documentación clínica, en el art. 8, Las voluntades anticipadas, que, como ya hemos subrayado a lo largo del presente trabajo, ha sido la primera CA en brindar un marco normativo a las declaraciones anticipadas antes de que lo hiciera el Legislador orgánico-estatuario. L. n. 6/2002, Salud de Aragón, que trata el tema de las Voluntades anticipadas; con el decreto 100/2003, el gobierno de Aragón ha promulgado el Reglamento de Organización y el funcionamiento del Registro de Voluntades Anticipadas. Islas Baleares: l. n. 5/2003, de Salud de las Islas Baleares, donde en su art. 18 las define "Las voluntades anticipadas" al interno de la 1. De modificación (la n. 1/2006) especifica que "las voluntades anticipadas consisten en una declaración de voluntad unilateral emitida libremente”. Castilla-La Mancha con la l. n. 6/2005, sobre la Declaración de Voluntades Anticipadas en materia de la propia salud, v. anche il decreto 15/2006 che instituye el Registro de las voluntades anticipadas de la CA medesima. Paesi Baschi: l. n. 7/2002, de las voluntades anticipadas en el ámbito de la sanidad; v. También el decreto 270/2003 a través del cual viene instituido y regulado el Registro Vasco de Voluntades Anticipadas. Galicia: art. 5, Voluntades anticipadas, de la l. n. 3/2001, “reguladora del consentimiento informado y de la historia clínica de los pacientes”. Navarra con ley foral 11/2002, Sobre los derechos del paciente a las voluntades anticipadas, a la información y a la documentación clínica, luego modificada por foral 29/2003, por la que se modifica parcialmente la Ley Foral 11/2002 del 6 de mayo sobre los derechos del paciente respecto a las voluntades anticipadas, a la información y a la documentación clínica. Valencía: art. 17, Voluntades anticipadas, de la l. n. 1/2003, “de derechos e información al paciente de la Comunidad Valenciana”), de manifestaciones anticipadas de voluntad (Canarias: decreto 13/2006 "por el que se regulan las manifestaciones anticipadas de voluntad en el ámbito sanitario y la creación de su correspondiente Registro”), de declaración de voluntad vital anticipada (Andalucía: Ley 5/2003, “de declaración de voluntad vital anticipada”), de declaraciones de voluntad (Canarias: decreto 13/2006 "por el que se regulan las manifestaciones anticipadas de voluntad en el ámbito sanitario y la creación de su correspondiente Registro”), e incluso la de expresión anticipada de voluntades (Extremadura: Ley 10/2001, de Salud de Extremadura en su art. 11.5, “expresión anticipada de voluntades” cfr. También el art. 17 della l. n. 3/2005 “de información sanitaria y autonomía del paciente”); en ningún caso está presente la expresión de uso más común, o sea, la expresión voluntades anticipadas, es decir, la de testamento vital (Tal fórmula es empleada pocas veces en los textos legislativos: aparece, por ejemplo, en los Motivos de la ley foral 8/2011 (Navarra) "de derechos y garantías de la dignidad de la persona en el proceso de la muerte” como sinónimo de voluntades anticipadas. Incluso en la Ley 2/2010 de Andalucía, el art. 5 dedicado a las definiciones de los términos utilizados por la ley en el punto p) si lee que "[t]estamento vital: es un sinónimo de declaración de voluntad vital anticipada”. La expresión testamento vital aparece también en una decisión judicial, la STS 282/2009, FJ 4, pero como mera 'citación', derivando la cuestión hacia el istituto de la autotutela) (utilizada sobre todo en doctrina, la cual constituye la traducción más inmediata de living will, V. Al menos, ROMEO CASABONA, C.M ${ }^{\mathrm{a}}$., "Los testamentos biológicos y el rechazo de los tratamientos vitales", en URRACA, S.,(coord.), Eutanasia hoy: un debate abierto, Madrid, 1996, 264; DE MonTALVO JäÄSKELÄINEN, F., Muerte digna, cit.; CORERA IzU, M., “Testamento vital”, en Actualidad civil, n. 1/2014; CANTERo MartíneZ, J., La autonomía del paciente, cit.; LóPEZ SÁNCHEZ, C., Testamento, cit., 93; Marcos Del CANO, A.Ma ., Voluntades anticipadas, cit) o, en consonancia con lo previsto por el Convenio de Oviedo, “deseos expresados anteriormente”. 
fiduciario nominato dal paziente (o in mancanza un amministratore di sostegno ad hoc), ricreando così la struttura propria della relazione di cura» ${ }^{39}$.

Es necesario precisar que la ley n. 219 del 22 de diciembre del 2017 regula la institución de las DAT de acuerdo con el principio del consentimiento informado, y la decisión de proceder en tal sentido se debe al hecho que las DAT se configuran como una extensión lógica del principio de consentimiento.

El acrónimo DAT, como ya dicho, está compuesto por las letras iniciales de “disposición anticipada de tratamiento", tras la decisión del Legislador de utilizar el término “disposición” en vez de “directiva”, “declaración” o “testamento vital”.

En referencia a la elección apenas comentada, es oportuno también señalar que la decisión de abandonar toda alusión a los términos "testamento biológico" o "biotestamento" fue acogida en modo favorable ya que el concepto de "testamento" remite a una fase post mortem del suscriptor y posee un contenido esencialmente patrimonial (arts. 587 y sig. Cód. Civ.). Además, mientras que las DAT se refieren sustancialmente a las indicaciones de la voluntad válidas para cada tratamiento sanitario, el testamento biológico, por su propia naturaleza, posee, en parte, un contenido más restringido, o sea, limitado sólo a los tratamientos salva vida y, en modo más general, a los procedimientos de sostenimiento vital. Por lo tanto, se puede afirmar que el testamento biológico se limita a recoger las decisiones relacionadas con el fin de vida y que tiene por finalidad principal el indicar la interrupción o la omisión de tratamientos que pueden prolongar artificialmente la vida, determinando así un final "natural". El fundamento de la institución se basa, por lo tanto, no sólo en la autonomía de la persona en lo que concierte a las fases del fin de vida ${ }^{40}$.

Si para evaluar la repercusión normativo-aplicativa de las DAT es necesario analizar el contenido prescriptivo del instituto jurídico, seguramente, desde este punto de vista, cuenta con un cierto peso (al menos, aunque no exclusivamente, desde el punto de vista semántico) el empleo de lemas como “directivas”, “declaración” o “disposición”, representados por la letra "D” del acrónimo. De hecho, tal como se ha indicado - y en mérito a lo que se comentará más adelante - sería (rectius: habría sido) oportuno utilizar el término "directivas", dado que el significado de dicho término conlleva un efecto de tipo orientativo-vinculante que se pretende encontrar en un documento escrito y subscripto "ahora para entonces".

El debate parlamentario - especialmente en sede de Comisión - se concentró, en cambio, en los términos “disposición” y “declaración”. La palabra “declaración” precedentemente adoptada por el texto del proyecto de ley "Calabrò" presentado en la anterior Legislatura - en acepción (jurídicamente) semántica representa una mera voluntad no vinculante que se esfuma hasta hacer desvanecer todo acto de disposición realizado por la persona, mientras que “disposición” describe un acto imperativo que,

\footnotetext{
${ }^{39}$ En la definición provista por la Corte dei Gentili en el punto 4.3.2. del documento consultable en https://undirittogentile.it.

${ }^{40}$ Posición diametralmente opuesta a la aquí sostenida es la de DE MonTALVO JÄÄSKELÄINEN, F., Muerte digna y Constitución. Los límites del testamento vital, Universidad Pontificia Comillas, Madrid, 2009, 64 ss.; ID., Límites a la autonomía de voluntad e instrucciones previas: un análisis desde el Derecho Constitucional, en "Derecho y salud", n.20/2010, p. 84. A favor, en cambio, - siempre en la doctrina española - SEOANE, A., "Derecho e instrucciones previas", en Derecho y salud. Número Extraordinario XX Congreso, n. 22/2011, p. 19.
} 
por el contrario, no deja margen alguno de ambigüedad al accionar del médico (casi como si se impartieran órdenes, tal vez excesivamente vinculantes para el médico mismo, de las cuales éste, id est, no pudiera tomar distancia). Dicho en otro modo, si el término “declaración” lleva en sí una connotación fundamentalmente informativa, o sea, una mera comunicación al médico, el término "disposición”, en cambio, comporta un contenido "prescriptivo": decido (sólo yo) sobre mi salud. En ambos casos, por lo tanto, perdería valor todo intento (legislativo) de encontrar una solución equilibrada entre los dos pesos (autodeterminación del paciente y autonomía del médico) de la báscula.

Esta desviación es de naturaleza semántica, esto es, deberá en cualquier modo confrontarse con el objeto concreto de la ley que confiere contenido a la forma (también al lema), por lo cual es posible afirmar que el nomen non posee un peso tan decisivo ${ }^{41}$. Poco importa el nomen: lo que importa es el contenido de la norma.

En efecto, de la lectura de la ley pareciera que - aun refiriéndose a disposiciones - la materia hubiera sido regulada bajo la óptica del concepto de directivas, tras atribuir al contenido y al alcance de las mismas un carácter (lo más posible y no a priori) ${ }^{42}$ vinculante, como podría dar a entender el empleo del término “disposición”. De hecho, utilizando una terminología propia del código, es posible afirmar que no hay sólo una disposición en materia sino que persisten eximentes que sopesan la relación entre el médico y el paciente.

\section{LA VINCULACIÓN Y LA ACTUALIDAD DE LAS DISPOSICIONES ANTICIPADAS DE TRATAMIENTO}

\footnotetext{
${ }^{41}$ Incluso a sabiendas que nomina sunt consequentia rerum. Una anotación parece de utilidad también en lo que respecta el ordinamiento español. Si en España la Ley sobre la autonomia del paciente (art. 11 dela Ley 41/2002 del 14 de noviembre, básica reguladora de la autonomía del paciente y de derechos y obligaciones en materia de información y documentación clínica) se inclina por el empleo de la fórmula de instrucciones previas, las leyes autonómicas utilizan una pluralidad de sustantivos que fundamentalmente hacen referencia al mismo instituto jurídico aunque, no obstante, no ha faltado quien ha considerado que era necesario modificar el nombre del instituto al momento de enmendar la propia legislación, decidiendo de abandonar el empleo del término voluntades previas para hacer referencia a las instrucciones previas aduciendo las siguientes motivaciones: "El desarrollo de la autonomía del paciente no se circunscribe sólo a una asistencia actual del paciente, sino que también pretende proyectarse en el tiempo, de modo que aquél, en previsión de que pueda encontrarse en una situación futura en la que no sea capaz de expresar su voluntad, pueda dictar previamente instrucciones respecto a los cuidados y tratamiento de su salud, o, en su caso, al destino de su cuerpo y órganos tras el fallecimiento. Lo anterior evidencia la necesidad de la libre revocación en cualquier momento de las instrucciones dictadas. Es por ello que parece más adecuada la denominación de instrucciones previas en lugar de voluntad anticipada, ya que se corresponde con el fin de esta figura”. Así en el Preámbulo de la Ley 3/2005 (de la Comunidad Autónoma de Galicia) “de modificación de la Ley3/2001, de 28 de mayo, reguladora del consentimiento informado y de la historia clínica de los pacientes”. Sobre el uso de la terminología empleada, para todos cfr. DE MONTALVO JÄÄSKELÄINEN, F., Muerte digna, cit., pp. 47 y ss.

${ }^{42}$ Las directivas son «vincolanti relativamente alla direzione che indicano, ma non necessariamente in tutto il loro contenuto, che peraltro non potrà non formare oggetto di valutazione e interpretazione in primis da parte dello stesso medico», v. PATRONI GRIFFI, A., Le regole della bioetica tra legislatore e giudice, Editoriale Scientifica, Nápoles, 2016, p. 146. V. también, AMATO, S., "Il testamento biologico: dal parere del Comitato Nazionale per la Bioetica al disegno di legge Calabrò", en GENSABELLA FURNARI, M., y Ruggeri, A., (coords.), Rinuncia alle cure e testamento biologico. Profili medici, filosofici e giuridici, Giappichelli, Turín, 2010, p. 242.
} 
Analizando la cuestión, es posible afirmar que no tendría ningún sentido jurídico predisponer un instrumento para la redacción de un documento escrito cuando una persona pudiera hacer pleno uso de su capacidad de razón y de sentido, y estuviera predispuesta a asegurar su propio deseo, convicción y voluntad en caso de encontrarse en una situación de incapacidad, para luego no tomar en consideración (en cuanto no vinculante) las voluntades manifestadas en modo anticipado. Si esta última hipótesis tuviera lugar, se podría observar claramente que se perdería la ratio de la norma, la cual tiene como finalidad primaria la salvaguardia de la igualdad de tratamiento entre sujetos capaces e incapaces. El objetivo de la norma es, id est, eliminar tanto como sea posible la disparidad entre los individuos que por el sólo hecho de encontrarse en diferentes condiciones personales (capacidad, incapacidad), reciben tratamientos discriminatorios (que se reflejan en un goce asimétrico de los derechos fundamentales) y por lo tanto son tratados con modalidades disconformes al parámetro ex art. 3 de la Constitución ${ }^{43}$ que prohíbe la discriminación fundada sobre las «condizioni personali».

Hablar de vinculación, sin embargo, no significa incurrir en el riesgo de abandono terapéutico o en la falta de evaluación médica en caso de incongruencia entre el contenido de las DAT y eventuales nuevos tratamientos disponibles respecto al momento en el que fueron suscritas (así dicha: contextualización).

Antes de detenernos en la quaestio del grado de vinculación de las DAT, debemos determinar quién tiene la "capacidad” de redactarlas y cuál es la forma requerida para el documento.

Respecto al primer punto, considerando el requisito subjetivo, la suscripción de las DAT necesita de la plena capacidad de razón y de sentido de la persona, siempre que sea mayor de edad ${ }^{44}$. Es así que no se reconoce el mismo pleno derecho a los individuos de edad inferior a aquella prescrita para la capacidad general de acción responsable de la persona. Esta indicación legislativa es, en parte, un rasgo que puede ser señalado como desfavorable porque no es del todo coherente con las disposiciones legislativas que otorgan a los menores de edad la posibilidad de decidir sobre otros derechos personalísimos como, por ejemplo, el matrimonio (art. 84, ap. 2, cód. civ.). Hubiese sido pertinente no vincular la edad como requisito, lo que representaría un equilibrio entre autodeterminación y responsabilidad "in vitro", y sería preciso respetar la voluntad del menor, de sus intereses, dejando de lado la edad, y tomando en consideración "in vivo" de su capacidad de discernimiento y de su plena capacidad de poder decidir sobre sí mismo y sobre su propio cuerpo (considerando, entonces, la efectiva madurez), así como lo indica el art. 24, ap. 1, de la Carta de los Derechos Fundamentales de la Unión Europea $^{45}$. En ámbito italiano, y tomando como referencia la reciente l. n. 219 del 2017,

\footnotetext{
${ }^{43}$ FLICK, G.M., “Dovere di vivere, diritto di morire, oppure ...?”, www.federalismi.it, p. 17.

${ }^{44}$ Come sucede incluso para la normativa española. Es necesario subrayar en modo crítico que algunas normativas autonómicas reconocen la posibilidad de aplicar las instrucciones previas incluso a los menores maduros y a todas las personas; V. en doctrinas almeno VILLAR ABAD, G., "La regulación, cit., p. 358.

${ }^{45}$ Diritti del minore: «[i] minori hanno diritto alla protezione e alle cure necessarie per il loro benessere. Essi possono esprimere liberamente la propria opinione. Questa viene presa in considerazione sulle questioni che li riguardano in funzione della loro età e della loro maturità». Incluso el código deontológico, con la finalidad de incluir cada vez más a los menores en la participación a la formación de (sus) decisiones terapéuticas, aun luego de la reforma del 2014, dispone que el médico debe garantizar al
} 
se observa que, respecto al consentimiento informado (en estado de pleno uso de la propia capacidad), la voluntad del menor es, al menos, «tenuta in conto» y que la vinculación a ésta aumenta «in relazione all[']età [del minore] e al suo grado di maturità» ${ }^{46}$. Se verifica entonces una especie de «asimmetria» ${ }^{47}$ no razonable entre la posibilidad de expresar su propia voluntad en estado de conciencia y la falta de reconocimiento de la misma en caso que ésta fuera expresada "ahora para entonces".

En lo que respecta a los requisitos formales, se requiere el documento escrito. La ratio de tal condición coincide con la necesidad de garantizar la confiabilidad y la certeza de la voluntad del sujeto, en modo que sobre tal contenido escrito el médico pueda justificar la legitimidad de su accionar por el hecho de haber seguido las disposiciones indicadas o por no haberlas seguido, anotando previamente la motivación en la historia clínica del paciente. Si la intención que ha impulsado al Legislador hubiese sido esa, tal vez se ha ido más allá de las exigencias de una carga formal que se demuestra sobrecargada de varios e incómodos «orpelli» ${ }^{48}$ como la redacción «per atto pubblico o per scrittura privata autenticata» ${ }^{49}$. Las problemáticas son evidentes y, por lo tanto, para la predisposición de actos jurídicos se debería adoptar - en todos los ámbitos del derecho - la regla fundamental de la libertad de forma (el art. 1325 CC.), la cual debería valer especialmente en el caso aquí ilustrado, dado que se trata de decisiones evidentemente personales. En la parte final del período se acerca bastante a la libertad de forma cuando se prevé «scrittura privata consegnata personalmente dal disponente presso l'ufficio dello stato civile del comune di residenza del disponente medesimo, che provvede all'annotazione in apposito registro, ove istituito, oppure presso le strutture sanitarie ${ }^{50}$.

Tal como se ha indicado antes, la problemática fundamental de la institución de las DAT coincide con la validez y la eficacia de éstas en una perspectiva temporal: algunos argumentan sobre la posibilidad de conservarlas aun durante un eventual estado de incapacidad y otros, por el contrario, niegan dicho valor de “conservación” en cuanto un

menor los elementos de información útiles a la comprensión de su condición de salud así como de las intervenciones de diagnóstico y terapéuticas programadas, con el objetivo de hacerlo partícipe del proceso de decisión (art. 33), y debe también considerar sus opiniones respecto a las decisiones que lo afecten (art. 35).

${ }^{46}$ Art. 3, apartado 2, l. n. 219/2017.

${ }^{47}$ CARUSI, D., "Per una deliberazione auto-esaminata. Idee per una legge sul «testamento biologico»", Rag. prat., n. 1/2012, p. 317.

${ }^{48}$ RosSI, S., "I chiaroscuri della legge sul testamento biologico", www.laCostituzione.info, p. 2.

${ }^{49}$ Art. 4, apartado 6, l. n. 219/2017.

${ }^{50}$ Otra vez, tal vez, una cierta excesiva burocratización. De hecho, la presencia física del autor no puede ser siempre asegurada. Ésta no es garantía de autenticad de las DAT por lo que, seguramente, es posible que las entregue un delegado a través de un poder firmado y de una copia del documento de identidad. Tal situación es consentida incluso a la luz de lo dispuesto por el art. 4, apartado 6, de la citada ley en la medida en ésta afirma que «[n]el caso in cui le condizioni fisiche del paziente non lo consentano, le DAT possono essere espresse attraverso videoregistrazione o dispositivi che consentano alla persona con disabilità di comunicare». Es razonable que se pueda efectuar la entrega de las DAT a través de un poder, por ejemplo, en el caso de discapacidad motora. Suponiendo que las regiones - que adoptan modalidades telemáticas de gestión de historias clínicas o el archivo sanitario electrónico u otras modalidades informáticas de gestión de datos de las personas inscriptas al Servicio Sanitario Nacional - puedan, con un propio estatuto, regular la recolección de copias de las DAT, incluyendo los datos del fiduciario y su introducción en un banco de datos, dejando, de todos modos, al subscriptor la libertad de decidir si entregar una copia o indicar dónde pueden consultarse las DAT. 
documento escrito “ahora para entonces” sería intrínsecamente (podría decirse per definitionem) inactual ${ }^{51}$.

Para afrontar el tema de la actualidad (conservada o no) de las DAT es necesario considerarlas con atención respecto a dos dimensiones sobre las que puede incidir el pasar del tiempo, o sea, al consentimiento otorgado por el declarante durante la formulación de las DAT y al contenido mismo de la expresión de consentimiento. El contenido y su (posible) obsolescencia serán discutidos en el próximo párrafo. Es conveniente iniciar por la actualidad del consentimiento dado que este aspecto se revela decisivo al interno de la cuestión de la vinculación de las DAT: si el consentimiento carece de actualidad, en consecuencia el contenido expresado pierde eficacia.

Como dicho anteriormente, a menudo se sostiene que las DAT no sean eficaces en la actualidad dado que son elaboradas "ahora para entonces", lo que las privaría de eficacia, convirtiéndolas en siempre inactuales. El Legislador supera esta objeción doctrinaria atribuyendo al instituto un valor en el tiempo, lo que es correcto dado que en este modo se evita de caer en paradojas, considerando que el concepto de actualidad pretende transmitir en este caso un «requisito logico e non meramente cronologicotemporale» ${ }^{52}$, cosa que lleva al redactor a considerar la posibilidad de ejercitar el derecho de revocación o de modificación de la propia voluntad hasta el momento previo a la eventual pérdida de conciencia, y esto se debe a que no se otorga a nadie la posibilidad de «congetturare se e quali altri cambiamenti possano essere intervenuti nel soggetto nel tempo successivo alla perdita della coscienza» ${ }^{53}$.

La conclusión paradójica del hecho de no atribuir un valor jurídico-vinculante a las DAT es que, a fin de excluir la posibilidad de riesgo de inactualidad derivada del desfasaje temporal entre el momento en el que fueron redactadas y el momento de su aplicación, se mortifica la autonomía del enfermo hasta anularla, para dar paso al predominio del paternalismo médico sobre la manifestación de la voluntad expresada del paciente (inactual en sentido cronológico pero no en sentido lógico).

En caso de pérdida de conciencia, no es posible ni siquiera hipotizar una eventual voluntad distinta a la expresada en las $\mathrm{DAT}^{54}$ que, por lo tanto, sono per definitionem siempre actuales para la conciencia pero podrían no serlo respeto al contenido considerando posibles nuevos descubrimientos científicos y/o tratamientos no tomados en consideración al momento de la redacción del documento. Si la disposición es vinculante en una situación no modificada, el mero transcurso del tiempo no puede constituir por sí solo un motivo para negar validez a una manifestación de voluntad: «il fatto che la persona non abbia più la possibilità di revocare l'atto non è un motivo per

\footnotetext{
${ }^{51}$ NICOLUSSI, A., “Al limite della vita: rifiuto e rinuncia ai trattamenti sanitari”, Quaderni costituzionali, n. 2/2010, pp. 285 y ss.

${ }^{52}$ Comité Nacional de Bioética, Dictamen del 18 de diciembre del 2003, Dichiarazioni anticipate di trattamento, cit., 13. En GIUNTA, F., Il consenso informato all'atto medico tra principi costituzionali e implicazioni penalistiche, Ferrara, 1999, 5; D’AVACK, L., "Scelte di fine vita”, en VERONESI, U., (coord.), Testamento biologico. Riflessioni di dieci giuristi, Milán, 2006, p. 83. Contra RAZZANO, G., "Principi costituzionali ed ambito di applicazione del consenso informato”, Trattato di diritto e bioetica, cit., p. 33. ${ }^{53}$ Comité Nacional de Bioética, Dictamen del 18 de diciembre del 2003, Dichiarazioni anticipate di trattamento, cit., 13.

${ }^{54}$ Mori, M., Op. cit., p. 65; PICIOCCHI, C., Op. cit., p. 12.
} 
disconoscerle a posteriori la libertà che, compiendo l'atto, ha esercitato» ${ }^{55}$. Aclarada dicha presuposición, es posible afirmar que, sin duda, es preferible valerse de una voluntad evidentemente expresada aun si ésta fuera abstracta y atribuible a un momento no actual, en vez que de una incierta (más bien, no explicitada) en una circunstancia actual (en sentido cronológico) y concreta.

En conclusión, el consentimiento debe ser considerado actual por el solo hecho de ser sujeto a revocación o modificación en cualquier momento y no porque debe ser expresado en el momento de ser puesto en marcha. Desde esta prospectiva, la posibilidad de decidir "ahora para entonces" representa el corolario lógico del principio de autodeterminación y del consentimiento informado, que no retrocede en caso de incapacidad del sujeto titular ${ }^{56}$. Es así que en consideración de lo dicho anteriormente, se confirma la tesis según la cual las DAT son, per definitionem, vinculantes en la actualidad operativa.

Aquello que sobresale en orden a la actualidad de la voluntad expresada no es tanto la estrecha contextualización entre lo que se prevé y su actuación ${ }^{57}$ sino más bien la

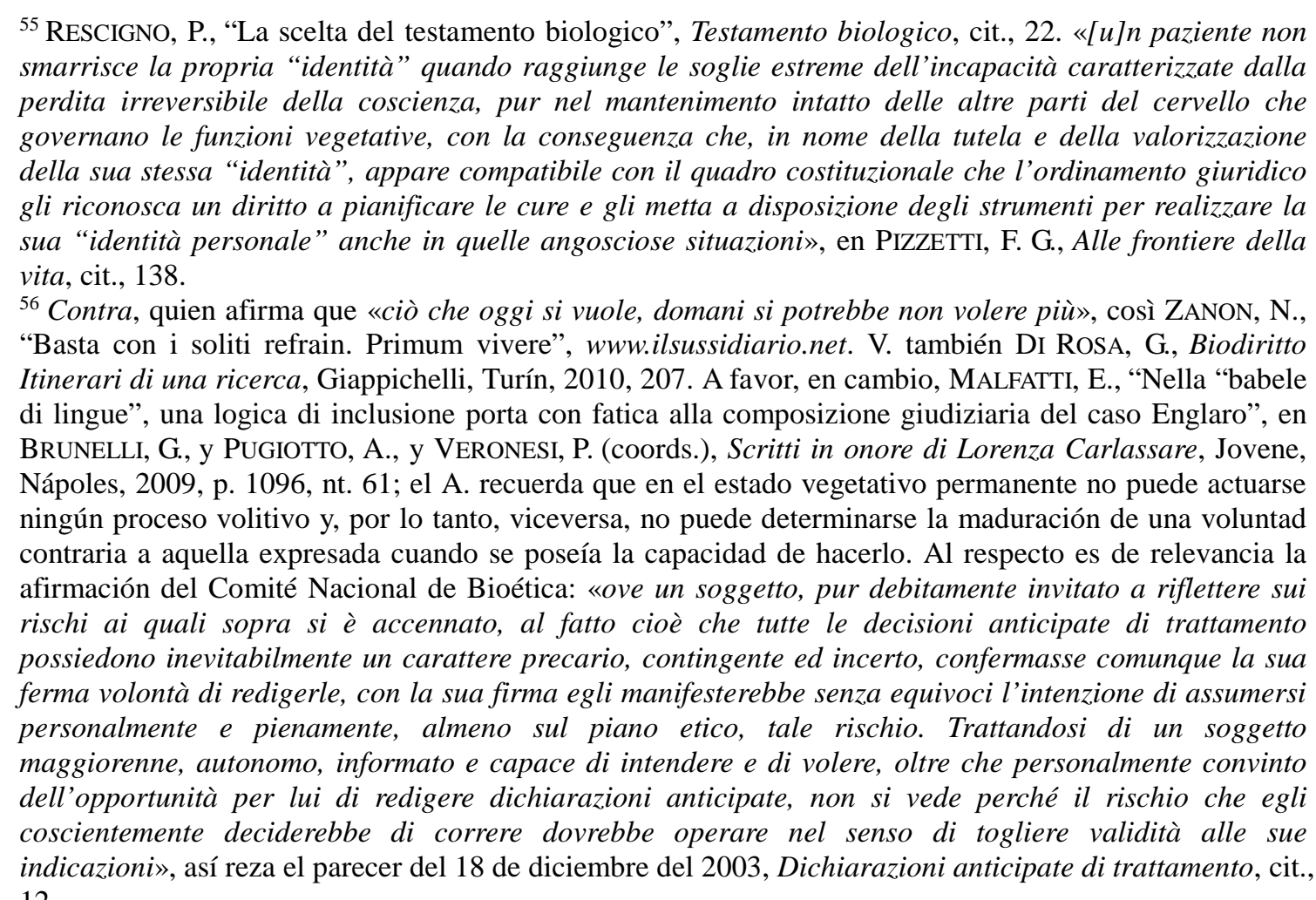
12.

${ }^{57}$ VAlLINI, A., "Introduzione al focus (II). Il diritto di rifiutare le cure e i suoi risvolti in tema di responsabilità del medico: spunti per una discussione multidisciplinare”, Rivista italiana di Medicina Legale, n. 2/2014, p. 501. Debería ser en tal modo no obstante la actualidad de las resoluciones que han avalado las decisiones de los médicos de no dar curso al disenso informado sobre las transfusiones de sangre debido a la imprevisibilidad del empeoramiento de las condiciones clínicas. Sin embargo, la decisión de no someterse a transfusión, como es sabido, es válida más allá de las condiciones de salud, v. Trib. Brescia, II secc. civ., 17 de junio del 2016, n. 1886 y Trib. de Milano, 13 mayo del 2015, n. 6052, ambas comentadas críticamente en CACACE, S., Ma quanto è debole il consenso informato! L'ultima giurisprudenza sul rifiuto dell'emotrasfusione. Apologia di un principio inutile (e qualche tentativo esegetico), Rivista italiana di Medicina Legale, n. 1/2017, pp. 18 y ss. Para una jurisprudencia aún más 
previsión del evento, que se concretiza en la voluntad del suscriptor de mantener su decisión «pur sapendo quello a cui sta andando incontro e sempre che quello che effettivamente poi avviene è ciò che era stato previsto e che era comunque da lui ragionevolmente prevedibile» ${ }^{58}$.

\section{ARGUMENTOS PARA UNA INTERPRETACIÓN RESTRICTIVA DE LOS LÍMITES DEL CONTENIDO DE LAS DISPOSICIONES ANTICIPADAS DE TRATAMIENTO. EL ROL DEL MÉDICO}

Tras ser abandonada la posibilidad de considerar a las DAT como no vinculantes (siempre y en cualquier caso) - cosa que era prevista en el proyecto de ley A.C. $\mathrm{n}^{\circ} 2350$ Disposiciones en materia de alianza terapéutica, de consentimiento informado y de declaración anticipada de tratamiento (así dicho: texto Calabrò, de la anterior Legislatura, la $\left.\mathrm{n}^{0} \mathrm{XVI}\right)^{59}$ - el actual Legislador define las DAT como documentos de contenido (altamente) vinculante.

Más allá de los requisitos subjetivos y objetivos, en el apartado 5 (y por remisión de éste al apartado 6 del art. 1) se refiere a lo aquí definido como contextualización de las DAT y, en consecuencia, a los límites inherentes a tal institución. Es gracias a la actualización (histórica) de las DAT que se evita el equívoco generado por la falta de empleo del lema "directiva” (que se refiere a la vinculación, aunque si bien no absoluta, de su contenido). Y de hecho, no se debe «aver paura di parlare di vincolatività» ${ }^{60}$, dado que ésta implica no una aplicación mecánica (de automaticidad casi "robótica") ${ }^{61}$ y acrítica, sino más bien una actuación "sustancial" de la voluntad expresada a la luz de las imprevistas circunstancias concretas: se podría decir que (como se subrayará más adelante) se escribe “disposición” pero se lee “directiva”. Delante a una previsión hipotética por naturaleza, «la vincolatività non toglie, ed anzi presuppone, che i medici siano chiamati a verificare la congruità delle direttive rispetto alla situazione data» ${ }^{62}$.

Se suele afirmar que, en presencia de las DAT vinculantes, la reducción de la figura del médico a mero burócrata sea una evidencia. Aunque así no sea. En el plano de las relaciones, el médico desenvuelve una función decisiva para la salvaguardia de la salud (la cual no es sólo física) del paciente. De hecho, la vinculación de las DAT no suprime, sino que confirma el rol central del médico, quien posee tarea esencial de controlar la

reciente v. PAPINI, F., Rispetto della persona umana o divieto di rifiutare le emotrasfusioni per motivi religiosi?, Rivista italiana di Medicina Legale, n. 1/2017, pp. 99 y ss.

58 Trib. Roma, GUP, 23 de julio - 17 de octubre del 2007, n. 2049 (v. p. 57).

${ }^{59}$ Varios de los usos lexicales “forzados" presentes en aquel texto eran (tal vez) debidos a la intención de vincular en modo indisoluble la ley (general y abstracta) a la situación (un hecho particular), cayendo, en tal modo, en la hipótesis de que hard cases make bad laws: frase célebre del juez americano Oliver Wendwull Holmes citada por RoDOTÀ, S., "La nuova legge truffa”, La Repubblica del 15 de febrero del 2009.

${ }^{60}$ Borsellino, P., Audizione presso la XII Commissione, sesión nº 6 del martes 9 de abril del 2016.

${ }^{61}$ En tal modo lo conciben y argumentan en modo crítico EUSEBI, L., Introduzione al focus (I). Menomazioni gravi della salute: "diritto di vivere" o diritto di morire"? Questioni aperte circa le dichiarazioni di rifiuto delle terapie, p. 486; CORNACCHIA, L., Profili giuridico-penali del rifiuto delle cure, ambos en Rivista italiana di Medicina Legale, n. 2/2014, p. 534. En el sentido propuesto por el texto, en cambio, MANTOVAni, M., “Biodiritto e problematiche di finevita”, Criminalia, 2006, p. 68.

${ }^{62}$ CARUSI, D., Op. cit., p. 316. 
congruencia de las DAT respecto a la situación concreta. Es menester del médico evaluar la correspondencia entre las previsiones escritas "en ese entonces”, en el momento de capacidad (en previsión hipotética), y la concreta situación en que se encuentra el paciente (“ahora”).

La responsabilidad del médico comporta la obligación de anotar en la historia clínica las decisiones adoptadas durante la evaluación de conformidad entre lo declarado y lo relevado, sin que sea posible dar curso a las indicaciones escritas solamente en el caso en que aquello que haya sido hipotizado no fuera, dada la circunstancia concreta, referible a la situación clínico-diagnóstica-prognóstica particular y actual.

El Legislador ha especificado el ámbito en el que se debe mover el médico cuando decide dar curso o no dar curso a las DAT redactadas por el declarante, con la previsión de la obligación de motivación escrita de las razones en caso de eventual negación a adecuarse a las disposiciones. Las motivaciones - que, claramente, no pueden ser aquellas de no procurar la muerte al paciente (no se está disciplinando la materia eutanásica) - deben ser siempre respetuosas del derecho a la autodeterminación ${ }^{63}$. De aquí que, por lo tanto, eventuales justificaciones podrían coincidir con la demostración de la no actualidad de la elección realizada en su momento porque, por ejemplo, el período temporal transcurrido desde la subscripción permitiría a los avances científicos de dar respuestas a problemáticas inimaginables y a efectos no imaginados hasta hace poco tiempo atrás ${ }^{64}$.

En esta misma dirección (vinculación y actualidad de las DAT), además de la doctrina ${ }^{65}$, también se ha expresado el Comité Nacional de Bioética, adoptando en diciembre del 2003 un parecer sobre las Declaraciones anticipadas de tratamiento en cuyo texto se lee que «ogni persona ha il diritto di esprimere i propri desideri anche in modo anticipato

\footnotetext{
${ }^{63}$ Sin perjuicio del hecho que la mera mención a la autodeterminación lleva en sí el valor intrínseco de actualidad: «tra i due sacrifici [rispettare una volontà anche non attuale o porla nel nulla perché non più attuale] sembra di maggiore entità quello che fa scaturire dall'incertezza relativa sulla attualità della volontà una violazione certa dell'ultima volontà conosciuta» (SANTOsuOsso, A., "A proposito di 'living will' e di 'advance directives': note per il dibattito”, Politica del diritto, n. 3/1990, p. 487); «quando la volontà è condizionata al verificarsi di fatti futuri, il requisito della sua attualità subisce una dilatazione, nel senso che la volontà è attuale dal momento in cui è stata manifestata fino al verificarsi della condizione futura, salvo che non sia intervenuta una sua revoca» (GIUNTA, F., "Diritto a morire e diritto penale”, Rivista italiana di diritto e procura penale, 1997, p. 108).

${ }^{64}$ Este eventual alejamiento entre lo previsto y lo verificado hubiera podido limitarse (aunque la decisión del Legislador no sigue dicha línea) previendo una vigencia temporalmente ilimitada de las DAT. Por ejemplo, el límite temporal (entre los tantos establecidos en la doctrina, TRIPODINA, C., Il diritto nell'età della tecnica, cit., 106) de cinco años (término sólo indicativo) representa la posibilidad de actualizar en modo obligatorio (sobre la irracionalidad del establecimiento de tal obligación v. TRIPODINA, C., Il diritto nell'età della tecnica, cit., 106; sobre la soportabilidad de tal carga, v. PIZZETTI, F.G., Alle frontiere della vita, cit., p. 254) la predisposición de la voluntad transfigurada en las DAT y de valerse de eventuales innovaciones científicas. En el mismo sentido del texto -incluso en España la vigencia de las DAT es temporalmente ilimitada - la doctrina española: LÓPEZ SÁNCHEZ, C., Testamento vital y voluntad del paciente (Conforme a la Ley 41/2002, de 14 de noviembre), Dykinson, Madrid, 2003, p. 125. Sobre la oportunidad de una previsión que obligue a la actualización periódica de las instrucciones previas véase también SEOANE, J.A., "Derecho y planificación anticipada de la atención: panorama jurídico de las instrucciones previas en España”, en Derecho y salud, n. 14/2006, 289; DíEZ RODRIQUEZ, J.R., "Legislación estatal y autonómica sobre voluntades anticipadas", en MARCOS Del CANO, A.M ${ }^{\text {a., (a cura }}$ di), Voluntades anticipadas, Dykinson, Madrid, 2014, pp. 121 y ss.

${ }^{65}$ CASONATO, C., "Le direttive anticipate”, cit., pp. 4 y ss.
} 
in relazione a tutti i trattamenti terapeutici e a tutti gli interventi medici circa i quali può lecitamente esprimere la propria volontà attuale [... Y, por lo tanto, que] se il medico, in scienza e coscienza, si formasse il solido convincimento che i desideri del malato fossero non solo legittimi, ma ancora attuali, onorarli da parte sua diventerebbe non solo il compimento dell'alleanza terapeutica che egli ha stipulato col suo paziente, ma un suo preciso dovere deontologico: sarebbe infatti un ben strano modo di tenere in considerazione i desideri del paziente quello di fare, non essendo mutate le circostanze, il contrario di ciò che questi ha manifestato di desiderare e volere. È altresì ovvio che se il medico, nella sua autonomia, dovesse diversamente convincersi, avrebbe l'obbligo di motivare e giustificare in modo esauriente tale suo diverso convincimento, anche al fine di consentire l'intervento del fiduciario o curatore degli interessi del paziente» ${ }^{66}$. El rol del médico continúa siendo de extrema relevancia ${ }^{67}$ dado que en las DAT es siempre posible reconocer una evaluación "actual” de los progresos científicos en medicina; y es por eso que a las disposiciones de las DAT no se les dará curso en automático, sino que se las llevará a cabo luego de efectuar adecuadas evaluaciones de lo que e declarante había puesto por escrito en autonomía y responsabilidad, por otra parte garantizado por el fiduciario ${ }^{68}$.

No obstante lo dicho - y considerando el "agrio" debate desarrollado en torno a la presentación y a la discusión respecto al proyecto de ley "Calabrò" durante la Legislatura XVI -, merecen un reconocimiento a parte las disposiciones presentes en la ley para las cuales la “disposición” posee carácter vinculante para el médico. En plena continuidad con el Convenio de Oviedo, se prevé que el médico puede desatender ${ }^{69}$ las DAT (aunque no exclusivamente) en el caso en que esas no respondan a lo que el paciente había previsto "ahora para entonces", dado que en el arco de tiempo transcurrido entre su redacción y su aplicación se han podido introducir innovaciones técnico-científicas que han implicado su obsolescencia, o sea, su superamiento.

Por lo tanto, las DAT serán (plenamente) vinculantes respecto al contenido siempre y cuando no se alcance el límite que obstacule su puesta en marcha, o sea, la en presencia de (eventuales) justificaciones que demuestren la no actualidad de la decisión tomada en aquel momento.

\footnotetext{
${ }^{66}$ En la página 15 del Dictamen del Comité Nacional de Bioética.

${ }^{67}$ Cupelli, C., Libertà di autodeterminazione terapeutica, cit., 129. Las posibilidades de que al médico se le reconozcan cada vez más las propuestas de evaluación con finalidad decisoria, incluso considerando que «[p]oiché la pratica dell'arte medica si fonda sulle acquisizioni scientifiche e sperimentali, che sono in continua evoluzione, la regola di fondo in questa materia è costituita dalla autonomia e dalla responsabilità del medico che, sempre con il consenso del paziente, opera le scelte professionali basandosi sullo stato delle conoscenze a disposizione», SCC n. 282/2002, punto 4 F. J.

${ }^{68}$ El contenido de las DAT responde a criterios de naturaleza moral, dado que éste se encuentra estrechamente ligado a la imagen que cada uno posee de sí mismo y que tal vez pretenda dejar a los demás, y con la percepción de la propia humanidad y dignidad, en CASONATO, C., "Consenso e rifiuto delle cure in una recente sentenza della Cassazione”, Quaderni costituzionali, n. 3/2008, p. 547.

${ }^{69}$ Hubiese sido más adecuado el empleo del verbo "no aplicar" dado que una previsión no se aplica a una determinada circunstancia si ésta entra en discrepancia con la primera; el “desatender”, en cambio, se aleja de dicha evaluación objetiva de los hechos por referirse a una evaluación de oportunidad de carácter subjetivo. De hecho, las expectativas caen exactamente cuando son desatendidas.
} 


\section{A) Los controlímites de operatividad de las disposiciones anticipadas de tratamiento.}

Definir las DAT como actos (potencialmente) ${ }^{70}$ vinculantes significa tomar en serio la intención de conformidad reduciendo al mínimo la posibilidad de distanciarse del contenido escrito por la tutela del principio de libertad personal. Precisamente por esto, no obstante que al inicio del presente párrafo se dijera que los puntos de fuerza son relevantes y de no poca importancia, con tal afirmación se pretende no omitir los diversos puntos críticos presentes en el texto de ley o subestimar su peso.

Dejando de lado la quaestio sobre la decisión tomada por el Legislador sobre el uso del término disposición en vez de directiva - sin que ello constituya una cuestión secundaria e irrelevante -, el análisis debe concernir, sobre todo, el contenido y la entidad (además de los límites, rectius los controlímites, de operatividad) de las DAT. Íntimamente conectada al rol del médico en presencia de una DAT, la previsión que dispone los eximentes para la aplicación es de difícil interpretación. La norma legal no limita la posibilidad de desatender el contenido de las DAT al hecho de ser (convertirse en) obsoletas, lo que representa una circunstancia que para nosotros hubiese debido constituir la única posibilidad de falta de aplicación. De hecho, «[f]ermo restando quanto previsto dal comma 6 dell'articolo 1, il medico è tenuto al rispetto delle DAT, le quali possono essere disattese, in tutto o in parte, dal medico stesso, in accordo con il fiduciario, qualora esse appaiano palesemente incongrue o non corrispondenti alla condizione clinica attuale del paziente ovvero sussistano terapie non prevedibili all'atto della sottoscrizione, capaci di offrire concrete possibilità di miglioramento delle condizioni di vita» ${ }^{71}$.

Si el texto original se limitaba a contemplar posibles desatenciones de las «terapie non prevedibili all'atto della sottoscrizione, capaci di assicurare possibilità di miglioramento delle condizioni di vita» ${ }^{72}$, hoy la ley ha extendido la no vinculación de las DAT también a los casos en que las mismas «appaiano manifestamente incongrue o non corrispondenti alla condizione clinica attuale del paziente». El «manifiestamente incongruo» podría dar lugar a una discrecionalidad de juicio por parte del médico que excede el justo equilibrio entre las dos partes de la alianza terapéutica, motivo por el cual dicha frase debe ser correctamente interpretada ${ }^{73}$.

Si el concepto de «manifiestamente congruo» remite a la cuestión de cómo se escriben las DAT (en el punto infra), respecto al concepto de «miglioramento delle condizioni di vita» es necesario indicar que dicho concepto se refiere no a las meras condiciones clínicas que evalúan el estado de la vida biológica, sino a la vivencia y a la experiencia de la existencia, o sea, a la vida biográfica de la persona, cuya titularidad no puede, de ningún modo, ser delegada totalmente, como si fuera un objeto, al saber-poder médico

\footnotetext{
${ }^{70}$ Entendida en este modo, la cuestión pierde la complejidad que generalmente se le atribuye: MEOLA, F., “Sul diritto di rifiutare le cure fino a lasciarsi morire”, Rassegna di diritto pubblico europeo, n. 1/2013, p. 122.

${ }^{71}$ Art. 4, apartado 5, l. n. 219/2017 (cursiva mía).

${ }^{72}$ Como previsto en el art. 3 del Acto parlamentario 1142 Norme in materia di consenso informato e di dichiarazioni di volontà anticipate nei trattamenti sanitari.

73 ADAMO, U., “Consenso informato e disposizioni anticipate di trattamento: finalmente la legge”, www.laCostituzione.info, 15 de diciembre del 2017, p. 3.
} 
mas debe permanecer a disponibilidad, en modo responsable, del sujeto que es conscientemente interesado a ésta.

Las decisiones positivizadas en las DAT no comprenden las terapias evaluadas en su generalidad (dimensión científica del tratamiento) sino que toman en cuenta la calidad de vida del subscriptor y la eficacia concreta de la terapia. Lo que se está afirmando aquí es que una cosa es la mejoría general de las condiciones de vida y otra cosa distinta es la calidad de la misma. Por supuesto, desde la perspectiva del saber médico, puede considerarse como mejoría de las condiciones de vida incluso al sólo restablecimiento del equilibrio de las funciones fisiológicas en un paciente que, de todos modos, permanece en una condición de inconciencia permanente. Ahora, ¿dicha situación puede determinar la no vinculación de las DAT? La respuesta no puede ser - por todo lo dicho anteriormente - que negativa. Sin embargo, no puede omitirse que existen posibles espacios interpretativos contrarios a aquél propuesto en esta sede, siempre factibles, y en los cuales resultan relevante la dicotomía entre la vida biológica y la vida biográfica a través de la interpretación de los límites a la vinculación de las DAT a la luz de la tutela del principio personalista, siendo las DAT, justamente, una expresión del principio de autodeterminación.

La estrecha relación entre el instituto tratado y el principio del consentimiento informado es también explicitado en la remisión (si bien inapropiada, como se verá más adelante) del apartado 5 del artículo 4 al apartado 6 del artículo 1 en la parte en la cual, en el segundo artículo, disciplinando el consentimiento informado, se explicitan los límites que se imponen a la legítima expresión de la voluntad del paciente expresada en modo anticipado respecto a la situación dada. Esta remisión supone la pérdida de la vinculación de las DAT en caso de solicitud de «trattamenti sanitari contrari a norme di legge, alla deontologia professionale o alle buone pratiche clinico-assistenziali»; en tales casos, se consiente al médico de desatender las disposiciones anticipadas de tratamiento.

La remisión a tal previsión se demuestra carente de valor, o sea, altamente "peligrosa" por las consecuencias que podría provocar sobre el instituto de las DAT. Dejando de lado las dificultades que podría acarrear la redacción de una Disposición con contenido de facere (en el momento en que el contenido típico es un pedido de abstención y/o de rechazo), se puede - con una cierta facilidad - tildar de inútil la previsión por la cual no es posible solicitar tratamientos contrarios a las normas de ley y a las buenas prácticas clínicas. Por lo tanto, el primer y el tercer límite (el segundo será tratado más adelante) resultan poco innovativos por ser (ya) inherentes al ordenamiento.

Para la norma legal no tendrán curso las DAT si, por ejemplo, contuvieran indicaciones a favor de comportamientos pertenecientes a ámbitos delictuales para la normativa en vigencia y, por lo tanto, para el código penal, que prohíbe, por ejemplo, las prácticas eutanásicas. Dicha circunstancia, evidentemente, no puede evitarse a través de una previsión "testamental" justificada por ser parte de una disposición anticipada de tratamiento. No se daría curso, por otra parte, ni siquiera a eventuales pedidos de ensañamiento terapéutico y, por lo tanto, al empleo de tratamientos no válidos a nivel científico o incongruentes o exuberantes.

El segundo límite coincide con el respeto de las buenas prácticas clínico-asistenciales, es decir, con el complejo de conocimientos técnico-científicos inherentes a la profesión sanitaria que se materializa en el criterio de evaluación médica realizada por el 
profesional, quien tiene en cuenta tanto las características particulares de la profesión, de su complejidad y de la importancia de la vida del paciente, así como del estado del enfermo o de su propia organización sanitaria, con el objetivo de calificar dicho procedimiento como acorde o no acorde a la técnica normalmente ejercitada $\mathrm{y}$ practicada. Incluso, tal previsión de la ley, sin embargo, no es convincente, y, claramente, requiere una puntualización interpretativa, juzgada - por el autor del presente ensayo - más que oportuna. Mientras tanto, el límite coincidente con el respeto de la buena práctica médica - y, por lo tanto, del complejo de conocimientos técnicocientíficos inherentes a ésta -, es decir, la negación del derecho de pretender un tratamiento cualquiera, incluso uno inapropiado o desproporcionado, está ya reconocido por la práctica judicial ordinaria. Ampliamente, la previsión no debe ser interpretada en el sentido de consentir la admisión de las (legítimas) solicitudes de facere en cuanto serían las únicas en línea con las buenas prácticas, ni tampoco aquellas cuyo contenido pudiese ser considerado como negativo por solicitar un non facere y, por lo tanto, un rechazo al tratamiento que sería siempre (y por definitionem) contrario a esas. En efecto, para el Legislador, las DAT representan la máxima expresión de la autodeterminación del individuo, desde el momento en que se reconoce que el límite de la buena práctica vale no sólo en el caso de que una persona solicite una intervención o un tratamiento, sino que vale aun cuando solicite que no se le haga. Por otro lado, el rechazo al tratamiento ha encontrado lugar en la normativa jurisprudencial hace más de diez años. El Legislador, de hecho, respecto al otro derecho que encuentra fundamento en el principio de la autonomía - el consentimiento informado -, ha ya previsto (ex art. 1 de la misma ley $)^{74}$ que el paciente debe expresar su consentimiento para cualquier estudio diagnóstico o tratamiento sanitario, el cual es plausible de ser rechazado en todo momento; tanto en el primero como en el segundo caso $^{75}$, no se indica ningún límite a la obligación de tratamiento incluso en caso de tratamiento salva vida ${ }^{76}$. La ratio de la ley es la tutela, en modo elevado y completo, del derecho a la autodeterminación de la persona, para la cual se predisponen todas las condiciones favorables para que pueda anticipar un eventual futuro estado de inconciencia tomando una decisión actual en

\footnotetext{
${ }^{74}$ Art. 1 que configura correctamente la relación que se crea en el contexto del tratamiento como un espacio en el que se confrontan, por un lado, los médicos que deben proyectar los interventos a realizarse y sus posibles consecuencias (positivas y negativas), incluso respecto a la no realización de los mismos, y, por otra, los pacientes, que no ya no son más considerados como incapaces de poder decidir. De igual modo también la doctrina española cuestionada en la portada dell’art. 11, ap. 3, Ley 41/2002 (“No serán aplicadas las instrucciones previas contrarias al ordenamiento jurídico, a la «lex artis», ni las que no se correspondan con el supuesto de hecho que el interesado haya previsto en el momento de manifestarlas. En la historia clínica del paciente quedará constancia razonada de las anotaciones relacionadas con estas previsiones”) Vid., SILVA SÁNCHEZ, J.M., “Los “documentos de instrucciones previas” de los pacientes (artículo 11.1 Ley 41/2002) en el contexto del debate sobre la (in)disponibilidad de la vida”, en La Ley, n. 4/2003, p. 1663 y ss.; GALLEGO RIESTRA, S., "Las instrucciones previas y su regulación jurídica”, en Gascón Abellán, M., y GonzÁlez Carrasco, Ma.C., y CANTERo Martínez, J., (coords.), Derecho sanitario y bioética. Cuestiones actuales, Tirant lo Blanch, Valencia, 2011, p. 509.

${ }^{75}$ Art. 1, ap. 5, de la l. n. 219/2017.

${ }^{76}$ «Il medico è tenuto a rispettare la volontà espressa dal paziente di rifiutare il trattamento sanitario o di rinunciare al medesimo $e$, in conseguenza di ciò, è esente da responsabilità civile o penale», art. 1 , ap. 6 , de la l. n. 219/2017.
} 
estado de conciencia y, por este motivo, los límites en subiecta materia deben ser sometidos a una rigurosa ponderación ${ }^{77}$.

Además, la mención a las buenas prácticas médicas citadas en modo general podría favorecer el empleo de prácticas locales, o sea, de prácticas realizadas a nivel nacional o regional pero también sujetas a vinculación territorial a través de las varias aziende sanitarie locali. En este modo, la incertidumbre que se pretendía superar con la ley tal vez podría ser evitada sin hacer referencia a aquellos aspectos que no se demuestran válidos erga omnes.

\section{B) Sobre la objeción de conciencia.}

El segundo límite legal a la vinculación de las DAT (el tercero ya ha sido expuesto antes) es el siguiente: "[i]l paziente non può esigere trattamenti sanitari contrari [...] alla deontologia professionale» ${ }^{78}$. La voluntad del paciente de solicitar determinados tratamientos sanitarios podría ser sujeta a la congruencia con las reglas profesionales, dando como consecuencia un paralelismo entre la deontología profesional médica y la ley ${ }^{79}$, despojandola de la supremacía de la que goza ${ }^{80} \mathrm{y}$, en consecuencia, subyugando la autodeterminación a las tradicionales prácticas sanitarias. La referencia textual al código deontológico en su totalidad - y por lo tanto incluso a su art. 22 que reconoce la autonomía y a la responsabilidad diagnóstico-terapéutica del médico - parece funcional a la apelación a la objeción de conciencia de los médicos por sobre la conciencia de los pacientes, lo que resulta ser una apelación implícita incluso en caso cuando «a fronte di tali richieste [los tres límites analizados], il medico non ha obblighi professionali».

Dejando de lado el fundamento constitucional ${ }^{81}$ de la objeción de conciencia ${ }^{82}$, detengámonos en el significado teórico y práctico que puede poseer dicha disposición,

\footnotetext{
77 También debido al hecho de que el derecho a la salud es un derecho «fondamentale», al respecto v. MoranA, D., La salute come diritto costituzionale. Lezioni, Giappichelli, Turín, 2015, p. 63 y ss; LUCIANI, M., "Salute (diritto alla) - Diritto costituzionale”, Enciclopedia giuridica, XXVII, Treccani, Roma, 1991, p. 2.

${ }^{78}$ Art. 1, ap. 6, ult. parte, de la l. n. 219/2017. Pareciera que el Legislador italiano se hubiese inspirado en el sistema francés, en el que, en algunos casos, se hace referencia expresa a la fuente deontológica, v. PuliCE, E., "La deontologia medica tra pluralismo assiologico e pluralità di sedi di giudizio", BioLaw Journal - Rivista di BioDiritto, n. 1/2016, p. 134.

${ }^{79}$ En tal sentido se manifestó la Comissione Giustizia del 1 de marzo del 2017.

${ }^{80}$ AINIS, M., "Se obiettano sul testamento biologico”, La Repubblica del 26 de febrero del 2017. En la misma dirección v. PISOTTI, G.G., "Fine vita e tribunali”, www.associazionelucacoscioni.it, 11s.; CUPELLI, C., Libertà di autodeterminazione, cit., 130.

${ }^{81}$ En lo que respecta a las distintas tesis doctrinarias véase PUGiotTO, A., "Obiezione di coscienza nel diritto costituzionale”, Digesto Discipline Pubblicistiche, X, Utet, Milán, 1995, pp. 242 y ss.; Di CosiMO, G., Coscienza e Costituzione. I limiti del diritto di fronte ai convincimenti interiori della persona, Giuffrè, Milán, 2000; PARIS, D., L'obiezione di coscienza. Studio sull'ammissibilità di un'eccezione dal servizio militare alla bioetica, Passigli, Firenze, 2011; GRANDI, F., Doveri costituzionali e obiezione di coscienza, Editoriale Scientifica, Nápoles, 2014; Di Cosimo G., y PugiotTo, A., y SiCARDi, S., La libertà di coscienza, Editoriale Scientifica, Nápoles, 2015.

${ }^{82}$ Siempre y cuando se pueda hablar de objeción de conciencia, de hecho, en presencia de una elección voluntaria (aquella de ser médico) y no de obligación (como hasta hace algunos años cuando los jóvenes italianos eran obligados a hacer el servicio militar e incluso ir a la guerra). Para todos, el persuasivo análisi propuesto por GEMMA, G., Obiezione di coscienza ed osservanza dei doveri, en MATTARELLI, S.,
} 
dado que resulta factible realizar una interpretación que convierta en inoperante el dispuesto objeto de atención crítica. Si es cierto - como es verdad - que las DAT representan la extensión lógica del consentimiento al tratamiento sanitario, y si es verdad - probablemente lo sea - que el contenido de las DAT es de naturaleza astensiva, primero sería necesario reflexionar sobre la posibilidad de expresar objeción de conciencia en presencia de una solicitud de disentimiento/revocación del tratamiento. El hecho de que tal situación no sea plausible de ser hipotetizada se deduce dado que el consentimiento informado representa un derecho fundamental y dado que la revocación del consentimiento al tratamiento (incluso) salva vida non se presenta como nexo de causalidad con el fin de vida, o sea, dando lugar al ejercicio del derecho de consentimiento/disentimiento informado no se procura la muerte sino que sólo se limita al tratamiento. En presencia de tal situación, el derecho de objeción de conciencia no puede ser ejercido y, de hecho, la actividad médico-quirúrgica en caso de ausencia de consentimiento, es categorizada como lesión personal voluntaria ${ }^{83}$ o como violencia privada $^{84}$. La finalidad que persigue la previsión de ley es la posibilidad de interrumpir el tratamiento sanitario y no la muerte del paciente; la renuncia es en dirección al uso “perseverante” de la técnica.

No se debería hablar, entonces, de derecho a la objeción de conciencia sino que se debería hablar de reticencia moral del médico en el llevar a cabo la voluntad del paciente (que es distinto del ejercicio de un derecho). El médico está obligado, por lo tanto, a dar un paso atrás en caso de expresión de un derecho fundamental resultante del principio de autonomía (voluntas aegroti suprema lex) ${ }^{85}$. La hipótesis de objeción de conciencia se configura como infundada y, por lo tanto, no puede ser considerada como legítimo ejercicio del derecho de conciencia ${ }^{86}$.

(coord.), Il senso della Repubblica. Doveri, Franco Angeli, Milán, 2007, pp. 57 y ss., espec. p. 67. Vid; Alonso Olea, M., y FANEgo CAstillo, F., Comentario a la Ley 41/2002, de 14 de noviembre, básica reguladora de la autonomía del paciente y de derechos y obligaciones en materia de información y documentación clínica, Thomson-Civitas, Madrid, 2003, p. 55; CASADO CASADO, B., "El testamento vital como instrumento jurídico de protección de derechos”, en RuIZ-RICO RuIZ, G., y MORENO, Mª. L., y TORRes Herrera, y PÉrez SOlA, N. (coords.), Principios y derechos constitucionales de la personalidad: su proyección en la legislación civil, Tirant lo Blanch, Valencia, 2010, p. 58; DoMíNIGUEz LUELMO, A., Derecho sanitario y responsabilidad médica (Comentario a la ley 41/2002, de 14 de noviembre, sobre derechos del paciente, información y documentación clínica), Editorial Lex Nova, Valladolid, 2003, p. 358. Sin que una objeción de conciencia (de masa) de parte de los operadores sanitarios anule las manifestaciones de voluntad predispuestas. V. todavía, VILLAR ABAD, G., "La regulación de las instrucciones previas en la Ley 41/2002”, en LIZARRAGA BONELLI, E., y GONZÁLEZ SALINAS, P., (coords.), Autonomía del paciente, información e historia clínica: estudios sobre la Ley 41/2002, de 14 de noviembre, Thomson, Madrid, 2004, p. 339.

${ }^{83}$ Art. 582 cod. pen.: «[c]hiunque cagiona ad alcuno una lesione personale, dalla quale deriva una malattia nel corpo o nella mente, è punito con la reclusione da sei mesi a tre anni».

${ }^{84}$ Art. 610 cod. pen.: «[c] hiunque, con violenza o minaccia, costringe altri a fare, tollerare od omettere qualche cosa è punito con la reclusione fino a quattro anni».

${ }^{85}$ Contra, para todos, PALMARo, M., Eutanasia: diritto o delitto? Il conflitto tra i principi di autonomia e di indisponibilità della vita umana, Giappichelli, Turín, 2012, p. 104.

86 «[P]or falta de justificación conceptual, ética y jurídica» SEOANE, J.A., “Objeción de conciencia positiva”, Revista de Bioética y Derecho, n. 32/2014, p. 38. Contra, siempre en la doctrina española, GUERRA VAQUERO, A.Y., "Las implicaciones de las voluntades anticipadas: los derechos del paciente y la responsabilidad del profesional sanitario”, en MARCOS DEL CANO, A.M ${ }^{\mathrm{a}}$, (coords.), Voluntades anticipadas, Dykinson, Madrid, 2014, p. 169. 
Más allá de las interpretaciones que se realizarán - por lo que aquí principalmente interesa - es preciso recordar que el paciente tiene, de todos modos, el derecho de obtener la interrupción del tratamiento sanitario rechazado, sin que la eventual abstención del médico que lo trata repercuta sobre su derecho. La abstención atañe más a la administración sanitaria que al paciente: de hecho, es la primera que debe organizar el servicio con el objetivo de garantizar los derechos fundamentales que coinciden con el derecho a la salud y debe, por lo tanto, facilitar todos los medios finalizados a la actuación concreta de tal derecho.

\section{C) La planificación compartida del tratamiento.}

Siempre a propósito del contenido de las DAT, nótese que éstas logran adquirir una plena actualidad sin perder la vinculación cuando el factor temporal no es determinante en la planificación compartida del tratamiento. A las DAT no se les reconoce sólo el papel (para nada accesorio) de planificar el tratamiento futuro cuando la persona se encuentra en una fase lejana al estado patológico, sino que también se les reconoce el rol de representar el modus operandi de la relación médico-paciente (-familiares) en lo que concierne a las elecciones sanitarias conscientes durante el proceso de tratamiento (o sea, en la fase patológica) a través de una planificación ${ }^{87}$. Tal previsión resulta presente en el art. 5 intitulado "Planificación compartida del tratamiento" (Pianificazione condivisa delle cure).

La diferencia con las DAT “clásicas” de las que trata el art. 4 es evidente. Si pueden ser redactadas en un momento "lejano al estado patológico" (tanto que éste no es ni siquiera in nuce), las DAT serán en re ipsa contextualizadas y eventualmente perderán el poder vinculante. La planificación compartida del tratamiento, en cambio, es más fehaciente porque nace ya en un contexto de relación entre el paciente y el médico y, por lo tanto, en presencia de un estado patológico que (con una cierta certeza) evolucionará, tal vez con consecuencias crónicas y con posibles estados de incapacidad, sobre todo, en casos caracterizados por una fenomenología patológica con diagnóstico fatal a causa de la incesante evolución de la enfermedad. El paciente, si está bien informado sobre el posible desenvolvimiento de la enfermedad, podrá compartir la planificación del tratamiento con los médicos y el equipo sanitario; a tal escenario deseado deberán adherir en modo absoluto.

En caso de que subsistan diversas posibilidades de resolución entre DAT y planificación compartida del tratamiento, predominará el contenido del segundo instituto dado que será el más reciente: voluntas posterior derogat priori. De todos modos, no se puede

\footnotetext{
${ }^{87}$ V. ORSi, L., y GiAnNini, A., y Vegano, M., y GristinA, G.R., "Le cure di fine vita in Italia: il problema e la sua possibile soluzione nella prospettiva dei clinici”, Rivista di BioDiritto, n. 2/2015, pp. 230 y ss. A la luz de un riquísimo aparato bibliográfico y desde una perspectiva exclusivamente clínica, tales AA. han afirmado que «modelli di ACP ritagliati sulle concrete condizioni di malattia hanno dimostrato che un approccio coordinato, sistematico, centrato sul paziente e i familiari e su un processo decisionale condiviso, che include discussioni riguardanti le cure di fine vita, migliora la qualità di queste ultime, riduce lo stress nei caragivers, evita cura e ricoveri inappropriati. In questo modo, direttive anticipate di trattamento (DAT), maturate nel contesto dell’ACP, diverrebbero più solide e affidabili», p. 231. V. también, ORSI, L., “Le cure palliative”, I diritti in medicina, cit., p. 613.
} 
prescindir de la voluntad de la persona, quien posee el «potere [...] di disporre del proprio corpo» ${ }^{88}$.

\section{LA NUTRICIÓN Y ALIMENTACIÓN ARTIFICIALES COMO TRATAMIENTO SANITARIO}

Retomando el debate que se desarrolló en la Cámara de Diputados durante la pasada Legislatura, es de elogiar (por lo que se dirá más adelante) la novedad legislativa debido al superamiento de la orientación según la cual la alimentación y la hidratación, en las diversas formas en las que la ciencia y la técnica pueden ponerlas a disposición del paciente, eran (jurídicamente) definidas como formas de sostenimiento vital destinadas a aliviar el sufrimiento hasta el final de la vida, sin que fueran consideradas como objeto de “disposición” (en ese momento “declaración”) anticipada de tratamiento.

El texto de la ley, por lo tanto, afronta en modo determinante una de las cuestiones políticamente más debatidas desde el "asunto Englaro", o sea, la “esencia” de la Nutrición e hidratación artificiales.

Además de acoger positivamente esta disposición legislativa (por otro lado, la única razonable desde el punto de vista científico ${ }^{89}$, es deber recordar que los organismos más importantes de regulación del sector ${ }^{90}$ consideran las Nutrición e hidratación artificiales como tratamientos específicamente terapéuticos. En plena sintonía con las argumentaciones elaboradas sobre el tema por la Casación ${ }^{91}$ y por la jurisprudencia de mérito $^{92}$, debe reconocerse a las intervenciones expuestas el carácter de verdaderos

\footnotetext{
88 SCC n. 471/1990, punto 3 F. J.

${ }^{89}$ Sobre la sensatez científica de las leyes v. SSCC nn. 282/2002 y 151/2009. Considerando la amplia jurisprudencia constitucional en materia, se puede afirmar que la insensatez de la decisión legislativa basada sobre adquisiciones de tipo científico se hace evidente en el empleo morboso de la discrecionalidad cuando, por ejemplo, se verifica un uso distorsionado del saber científico que no justifica dicha decisión normativa. Sobre tal punto, si se quiere, se remite a ADAMO, U., "Materia "non democratica” e ragionevolezza della legge”, Consulta online, n. 1/2018, pp. 1 y ss.

${ }^{90}$ GALAzzO, G., "Qualificazione dei trattamenti di nutrizione e idratazione artificiale e discrezionalità del legislatore”, Il diritto alla fine della vita, cit., pp. 199-212. V. también la Guía para el proceso de toma de decisiones relativas al tratamiento médico en situaciones del final de la vida, Consejo de Europa, Noviembre, 2014, pp. 12 y ss., y el Tribunal Europeo de Derechos Humanos (Grande Camera), 5 de junio del 2015, asunto Lambert y Otros contra. Francia.

${ }^{91}$ Cas. civ., sección I, 16 de octubre del 2007, sent. n. 21748, punto 7 de la Motivazione in diritto. En igual sentido también los célebres casos Cruzan del Tribunal Supremo de Estados Unidos (1990) y Bland de la House of Lords en Inglaterra, que han suspendido un tratamiento de sostén vital sin basarse en el principio de autodeterminación mas basándose en la obsolescencia del tratamiento (1993) - sobre dichos casos se remite a DWORKIN, R., Il dominio della vita, Milán, 1994, pp. 258-263. En modo diverso, las Nutrición e hidratación artificiales no constituyen tratamientos sanitarios para la Corte de Ap. de Milano, decr. del 26 de noviembre de 1999, para la cual la posibilidad de afirmar que las Nutrición e hidratación artificiales constituyan un tratamiento terapéutico todavía no representa una cuestión definida ni en ámbito médico ni en ámbito jurídico. Incluso el Comité Nacional de Bioética (Dictamen del 24 de octubre del 2008 Rifiuto e rinuncia consapevoli al trattamento sanitario nella relazione paziente-medico) reconoce que (incluso antes de la emanación de la primera ley) el ordinamento italiano «non ammette[va ...] l'imposizione forzata di un trattamento autonomamente e coscientemente rifiutato, pur se necessario al mantenimento in vita della persona», p. 6.

92 La hidratación ha sido reconocida como tratamiento por el juez tutelar de Módena en fecha 5 de noviembre del 2008, en el acto de nombramiento de un administrador de sostén. V. también Consejo de
} 
tratamientos sanitarios a la luz de la pluralidad de constataciones ya presentes, además, en el genuino sentido común.

Mientras tanto se detalla que el tratamiento terapéutico de las Nutrición e hidratación artificiales implica «un sapere scientifico, che è posto in essere da medici, anche se poi proseguito da non medici, e consiste nella somministrazione di preparati come composto chimico implicanti procedure tecnologiche» ${ }^{93}$.

La caracterización de verdaderos tratamientos sanitarios deriva, de hecho, de las siguientes constataciones: se trata de hidratación y nutrición de tipo artificial, implementados tras estudios y conocimientos científicos de la medicina en época moderna que requieren la intervención de profesionales del sector, es decir, de médicos especializados que representan las únicas figuras habilitadas para la suministración de tales tratamientos; la práctica médica en examen consiste en una verdadera suministración forzada de la preparación (compuesto químico) en forma líquida a través de dispositivos y máquinas específicas (por ejemplo, la sonda nasogástrica) y tienen como finalidad el proveer compuestos confeccionados en laboratorio: artificialidad en la preparación y en el acceso al contenido nutricional con modalidades técnicas sofisticadas.

Entre las posiciones más acreditadas que se contraponen a considerar a las Nutrición e hidratación artificiales como actos médicos ${ }^{94}$ - al contrario de lo que se sostiene en esta sede - figura seguramente la postura del Comité Nacional de Bioética, la cual se presenta desprovista de valor. En particular modo, se hace referencia al documento $L a$ alimentación y la hidratación de pacientes en estado vegetativo permanente, del 30 de septiembre de 2005. Según el prestigioso Comité, las Nutrición e hidratación artificiales son «forme ordinarie di assistenza di base», por lo que no resulta posible, por lo tanto, que éstas "possano essere considerat[e] "atti medici" o "trattamenti medici" in senso proprio, analogamente ad altre terapie di supporto vitale, quali, ad esempio, la ventilazione meccanica. Acqua e cibo non diventano infatti una terapia medica soltanto perché vengono somministrati per via artificiale». Los términos utilizados adquieren un significado distinto respecto a aquel generalmente atribuido ${ }^{95}$ : la nutrición y la hidratación artificiales se transforman en agua y comida, y el procedimiento llevado a cabo para su suministración no es catalogado como tratamiento sanitario ${ }^{96}$, aun

estado, secc. III, 2 de septiembre del 2014, n. 4460 (enésima decisión sobre el “asunto Englaro”) en la cual se lee que «[l] a decisione di somministrare al paziente l'alimentazione e l'idratazione artificiale è, in tutto e per tutto, il frutto di una strategia terapeutica che il medico, con il consenso informato del paziente, adotta, valutando costi e benefici di tale cura per il paziente, ed è particolarmente invasiva, per il corpo del paziente stesso, poiché prevede, nel caso della nutrizione enterale, addirittura l'inserimento di un sondino che dal naso discende sino allo stomaco o l'apertura di un orifizio, attraverso un intervento chirurgico, nell'addome», punto 38.3 pero v. todos los puntos, desde el 36.1 al 38.7 del Diritto. Al respecto EUSEBI, L., Introduzione, cit., 487.

${ }^{93}$ Cas. civ., secc. I, sent. n. 21748/2007, punto 7.6 de Motivi della decisione.

${ }^{94}$ V. también EUSEBI, L., "Laicità e dignità umana nel diritto penale (pena, elementi del reato, biogiuridica)”, en PICOTTI, L., (coord.), Tutela penale della persona e nuove tecnologie, Padova, 2013, p. 292.

${ }^{95}$ En tal sentido y eficazmente AgOSTA, S., "Se l'accanimento legislativo è peggio di quello terapeutico: sparse annotazioni al disegno di legge in materia di alleanza terapeutica, di consenso informato e di dichiarazioni anticipate di trattamento", Rinuncia alle cure e testamento biologico, cit., p. 283.

${ }^{96}$ Las Nutrición e hidratación artificiales no forman parte de los tratamientos «propriamente» sanitarios según RAZZAno, G., Principi costituzionali ed ambito di applicazione del consenso informato, cit., p. 35, 
presuponiendo una evaluación preliminar del médico a quien se le solicitaría solamente un «piccolo intervento iniziale» ${ }^{97}$, de fácil gestión, en una situación caracterizada por la «insussistenza di una condizione patologica autonomamente e progressivamente letale» ${ }^{98}$. Una vez transformado el significado de las cosas, en el Documento se llega a afirmar que «la richiesta nelle Dichiarazioni anticipate di trattamento di una sospensione si configura [...] come la richiesta di una vera e propria eutanasia omissiva, omologabile sia eticamente che giuridicamente ad un intervento eutanasico attivo, illecito sotto ogni profilo» ${ }^{99}$.

No está de más recordar que dado que la Constitución no especifica distinción alguna entre los diferentes tratamientos desde el punto de vista de las consecuencias que puede acarrear su rechazo ${ }^{100}$, la exclusión de la alimentación y de la hidratación como objetos de las DAT no encuentra razón de ser porque, en una fase extrema como la del fin de vida, todos los tratamientos se configuran como decisivos en la disminución del avance incontenible de la enfermedad y de la decadencia física ${ }^{101}$.

Incluso, queriendo aceptar la tesis de la negación de las Nutrición e hidratación artificiales como tratamiento sanitario ${ }^{102}$ (se recuerda que el Legislador no se ha expresado al respecto) no es comprensible el punto de vista que justifica la imposición a alimentarse e a hidratarse a una persona que no desee hacerlo ni el deber del médico de no dar curso a tal clara expresión de determinación ${ }^{103}$. Por lo tanto, es posible

dado que las mismas no son «funzionali alla cura di una patologia ma alla cura di base dovuta a chiunque». Su suspensión constituiría un acto ilícito por ser teleológicamente orientado a provocar la muerte del paciente.

${ }^{97}$ La suministración se demuestra forzada y por ese motivo viola en modo evidente los fundamentos de la autodeterminación, en el caso de que el sujeto que recibe el tratamiento haya expresado una posición contraria a tal práctica, más allá de la invasividad o non invasividad de la intervención (considero que el extracto entre comillas del Dictamen se refiera a tal circunstancia). Tal afirmación se revela aún más verdadera si se considera que, según la no tan reciente jurisprudencia constitucional, la extracción de sangre (práctica mucho menos invasiva respecto a la que se está haciendo referencia) es considerada una «pratica medica [seppur] di ordinaria amministrazione» e rientrante senza alcun dubbio tra le misure di «restrizione della libertà personale quando se ne renda necessaria la esecuzione coattiva perché la persona sottoposta all'esame peritale non acconsente spontaneamente al prelievo», así SCC n. 238/1996, punto 3.2 F. J. Dudas al respecto son manifestadas por A. D’AlOIA, Al limite della vita, cit., p. 262.

${ }_{98}$ D’AloiA, A., Al limite della vita, cit., p. 263.

${ }^{99} \mathrm{~V}$. el punto 8 del Dictamen L'Alimentazione e l'idratazione di pazienti in stato vegetativo persistente aprobado en la sesión plenaria del 30 de septiembre del 2005 (cursivas nuestras).

${ }^{100}$ LUCIANI, M., Diritto alla salute, cit., p. 11.

101 Agosta, S., Se l'accanimento legislativo, cit., 8: «che significato avrebbe, difatti, vietare l'interruzione di idratazione e alimentazione e non pure quella di una dialisi o di un antibiotico contro un'infezione o di un antitrombolitico o di un unguento antipiaghe? In quella "straordinaria" condizione di totale dipendenza, l'ammalato, pur regolarmente idratato ed alimentato, si spegnerebbe comunque tra atroci sofferenze (rispettivamente, per un blocco renale che non tarderebbe a venire, per l'inevitabile dilagare della pregressa infezione o per l'ulteriore aggravarsi delle piaghe da decubito): dal che si capisce come questo tipo di distinzione - algida ed asettica sulle pagine dei libri - sfumi, sino a diventare impalpabile, nella pratica, al punto da indurre a vietare l'interruzione di "qualunque" trattamento praticato al degente».

102 Habla de «sussidi vitali» que no pueden ser suspendidos dado que el resultado seguro e inmediato de sus suspensión es fatal: RUGGERI, A., "Le dichiarazioni di fine vita tra rigore e pietas costituzionale", Forum di Quaderni costituzionali, p. 10.

${ }^{103}$ En este caso se debería proceder con un tratamiento sanitario obbligatorio (TSO) pero, en tal modo, resultaría evidente que se trataría de un tratamiento sanitario. 
preguntarse si, dejando de lado si la cuestión de la hidratación y de la nutrición se configuran como un tratamiento sanitario (capaz de ser rechazado) o como un tratamiento asistencial (al que no se puede renunciar por su propia naturaleza), la suministración de las Nutrición e hidratación artificiales constituye una restricción a la libertad personal en el caso de imposición contra la voluntad expresada. La respuesta se orienta hacia la segunda posibilidad planteada, en cuanto cualquier intervención (de naturaleza sanitaria o asistencial) no solicitada o, de todos modos, no deseada por la persona, constituye una violación de la «sfera delle libere scelte personali» ${ }^{104}$.

Existen también otras posiciones que, aún considerando la hidratación y la alimentación como tratamientos sanitarios, argumentan que éstas deben representar una derogación a la posibilidad de ser objetos de las DAT.

A nosotros nos parece que no sea posible argumentar ${ }^{105}$ que una persona en plena posesión de sus facultades mentales, quien decidiera rechazar tales prácticas médicas, pueda ser obligada a soportar la suministración, en plena divergencia con la disposiciones constitucionales ex art. 32 de la Constitución. Si, de hecho, pueden considerarse como parte de las DAT todos los tratamientos sanitarios ordinarios, la exclusión de éstas como parte de las prácticas médicas no encuentra fundamentación fuera del ámbito ideológico, corriendo así el riesgo de no superar los cánones de la lógica.

A este punto debe justificarse que tanto las prácticas de alimentación como las de hidratación artificiales no forman parte de los tratamientos sanitarios obligatorios (para apreciar la ratio sobre la diferencia de tratamiento) y también que éstas no representan un genus particular del procedimiento médico.

Ahora, es bastante sencillo demostrar ${ }^{106}$ que no se está, en el caso disciplinado, en presencia de un tratamiento sanitario obligatorio: a) en cuanto el rechazo de las Nutrición e hidratación artificiales constituye una decisión exquisitamente individual que recae sólo en el sujeto que ha decidido autónomamente de aplicarlas, id est es clara la ausencia de la exigencia de la tutela de la salud pública; b) porque la imposición a un individuo de un tratamiento que tiene como finalidad el mantenerlo en vida contra su voluntad viola el respeto por la persona humana y, por lo tanto, de su dignidad, cosa que el art. 32 de la Constitución cita como límite de la legitimidad de los tratamientos sanitarios obligatorios; el provedimiento obligatorio impuesto debe puntar a impedir que la salud del individuo ocasione daño a la salud de los demás y a asegurar que la intervención prevista sea útil a la salud del paciente ${ }^{107}$ sin perjudicarla.

Por lo tanto, como conclusión, se afirma que las Nutrición e hidratación artificiales son, en todo sentido, tratamientos médicos. Una terapia médica, en caso de nutrición enteral (o sea, la nutrición a través del sistema digestivo con tubo de nutrición también denominado sonda nasogástrica) e, incluso, en caso de nutrición parenteral (es decir, la nutrición por vía venosa o subcutánea), es claramente un tratamiento artificial.

\section{EL FIDUCIARIO COMO INSTRUMENTO DE FLEXIBILIAZACIÓN Y DE TRÁMITE DE LA VOLUNTAD AJENA}

\footnotetext{
${ }^{104}$ MALFATTI, E., Op. cit., p. 1096.

${ }^{105} \mathrm{Al}$ contrario de PALMARO, M., Op. cit., pp. 30 y ss.

106 Pioggia, A., Brevi considerazioni sui profili di incostituzionalità, cit., p. 2.

${ }^{107}$ Ex multis, SSCC nn. 258/1994 y 118/1996.
} 
Las DAT constituyen disposiciones no sólo de instrucción, sino también de representación ${ }^{108}$.

Con el objetivo de flexibilizar el instituto y de garantizar la (potencial) vinculación, la ley (siguiendo las disposiciones presentes en otros países) también prevé la figura de un fiduciario al cual (si designado) se le puede confiar la ejecución de las "disposiciones". La figura del fiduciario (cuya designación, claramente, es optativa y no representa una obligación) posee el primordial objetivo de flexibilizar ${ }^{109}$ el contenido de las DAT para actualizarlos, evitando el surgimiento de conflictos en la aplicación de las mismas.

Las disposiciones anticipadas tendrán un peso diferente - y determinarán una ampliación o no del rol del fiduciario evitando posibilidad de contraste - en caso de referirse a una patología precedente o por la cual comienza un período de hospitalización (con respectivo pronóstico), o sea, en caso que éstas sean subscriptas cuando la persona se encuentra en plena salud. Para colmar las exigencias de una circunstancia coincidente con la segunda hipótesis (en la que se asiste a un ampliamento del papel del fiduciario), sería oportuno prever la posibilidad explícita de expresar en las DAT también los valores de referencia existenciales a los que aspira el subscriptor, con el fin de "sostener" al médico y al fiduciario en la concretización y en la actualización de su voluntad.

El fiduciario, en su delicadísimo rol, nunca debe hacer predominar su propia voluntad sino que debe "simplemente" ser un medio de la voluntad ajena (la del fiduciante, «vestendone i panni» ${ }^{110}$ ). El fiduciario debe desempeñar una función de vigilancia de la aplicación de las disposiciones y de cooperación con el médico: él es el sujeto al que se le reconoce la tarea de mediar, interpretar, actualizar y concretizar las DAT escritas "ahora para entonces” por la persona cuyos intereses es llamado a tutelar.

La figura de representante coincide con el rol que deberá asumir quien será designado por la persona que redacta el documento y que será, en caso de necesidad, su interlocutor en la relación con el médico o con el equipo sanitario, con el objetivo de garantizar el respeto de las DAT. Se ha escrito en caso de necesidad dado que la intervención aclaratoria del fiduciario es requerida (a la luz de lo dicho en el párrafo anterior, sólo si especificado $)^{111}$ en el caso que se verifique una incongruencia entre la situación realmente acontecida y las presuposiciones indicadas por el redactor de las disposiciones. En tales casos, la figura del representante puede resultar de fundamental relevancia. El representante designado tiene la exclusiva tarea de garantizar el respeto de la voluntad anticipada por parte de quien lo ha nombrado, basándose únicamente sobre el contenido ya manifestado en la redacción de las disposiciones; en ningún caso,

\footnotetext{
${ }^{108}$ PizzetTI, F.G., Alle frontiere della vita, cit., p. 7.

${ }^{109}$ S. AgostA, Bioetica e Costituzione, cit., p. 164.

${ }^{110}$ V. el documento Linee propositive per un diritto della relazione di cura, cit., punto 4.3.2. El fiduciario no podrá decidir jamás «al posto» del paciente, v. CRICENTI, G., I giudici e la bioetica, cit., pp. 107 y ss. Por la doctrina española: GonZÁLEZ MORÁN, L., "La figura y función del "representante” en la legislación sobre instrucciones previas (ley 41/2002 y legislación autonómica)”, en ADROHER BIOSCA, S., y De Montalvo JäÄskeläinen, F., y De los Reyes Corripio Gil DElgado, M., Y Veiga Copo, A.B., (coords.), Los avances del derecho ante los avances de la medicina, Aranzadi, Madrid, 2008, pp. 635 y ss. 111 Tal hecho debería ser válido en un sistema fisiológico. De hecho, en presencia de una DAT clara, el médico debería darle curso sin ningún tipo de oposición. El papel del fiduciario debería, por lo tanto, reducirse a cero.
} 
id est, puede suplir las posibles faltas de voluntad expresadas por su representado, debiendo limitar su función a mero “interlocutor", si bien privilegiado, en la relación con el médico.

El fiduciario no puede, bajo ningún punto de vista, representar en modo absoluto la titularidad de actos personalísimos que, en cuanto tales, no pueden ser "transferidos". Si así no fuera, éstos no serían indisponibles y el instrumento de las DAT, cuyo primordial objetivo es la tutela de los derechos fundamentales del individuo, incluso en caso de incapacidad - dejando así de lado el "paternalismo" médico -, perdería valor en su ratio esencial a causa de su inaceptable desvirtuación. Por lo tanto, la tarea del representante es solamente aquella de garantizar la eficacia de lo (ya) expresado en las DAT, excluyendo la representación por sustitución, en la que el representante decida autónomamente en nombre y en lugar del representado: no se puede decidir pleno iure sobre los derechos personalísimos y en consecuencia intransferibles.

La reconducción del fiduciario a sujeto no capaz de decidir plenamente "en lugar” del subscriptor es un rasgo dispuesto en modo intencional por el Legislador con el objetivo de reglamentar sobre la eventual aparición de contraposiciones entre los sujetos legitimados para expresar el consentimiento y el médico. Por otra parte, la función primordial que el fiduciario debe asumir es precisamente aquella de resolver ex ante los conflictos que puede desencadenarse a partir de la aplicación de una voluntad expresada "ahora para entonces".

Las controversias, cosa fisiológica al interno de cualquier sistema, pueden siempre surgir y su resolución deberá depender de la decisión del juez tutelar que actuará un procedimiento de garantía en tutela del sujeto vulnerable ${ }^{112}$. Si por tal motivo la remisión a la decisión de la autoridad judicial no es sustituible ${ }^{113}$, al fin de no caer en el riesgo de una excesiva «burocratizzazione» ${ }^{114}$ de la elección terapéutica, hubiese sido oportuno - considerado lo sostenido anteriormente - no introducir la modificación introducida durante el examen que tuvo lugar en la Cámara de Diputados. En el previsor art. 4, de hecho, el contenido de las DAT no se limitaba solamente al consentimiento o al rechazo de un determinado tratamiento, sino que se extendía hasta incluir las «convinzioni e preferenze» de la persona. Incluso a la luz de lo expresado en la decisión de la Casación sobre el “asunto Englaro”, de hecho, había sido prevista la posibilidad (claramente no la obligación) para quien hubiera redactado las disposiciones, de poner por escrito incluso las propias convinciones y los propios valores de referencia y, por lo tanto, de subscribir un conjunto de opiniones que dan sentido al propia vida y que

\footnotetext{
112 Todas estas reglas se establecen con el objetivo de garantizar una "genuina” expresión de voluntad que debe ser manifestada con la mayor cautela posible pero que, de todos modos, no pueden llegar al punto de negar a la persona la posibilidad de expresar sus propias convicciones debido a que nadie está, por definición, libre de condicionamientos. Tal afirmación - que rechazo por sus posibles paradójicas consecuencias - es, en cambio, sostenida por la acreditada doctrina que considera las elecciones de fin de vida como caracterizadas per definitionem por una falta de genuinidad: CARTABIA, M., "Alcuni interrogativi su libertà e autodeterminazione nei casi di fine vita”, en D’ALOIA, A. (coord.), Il diritto e la vita. Un dialogo italo-spagnolo su aborto ed eutanasia, Jovene, Nápoles, 2011, p. 27.

${ }^{113}$ La intervención de juez constituye y (siempre) constituirá una forma de control de la legitimidad de la decisión tomada (que debe llevarse a cabo) tutelando el interés de la persona incapaz.

${ }^{114}$ CASONATO, C., "A proposito del ddl sul testamento biologico. Una legge più realista del re”, Il Mulino, 1.
} 
representan el fundamento de las propias elecciones y preferencias en el proceso de la enfermedad y también en el fin de vida.

Por el contrario, no se ha optado por concebir el instituto como un documento en el cual pudieran ser explicitados (la praxis revelará si el estado de las cosas es realmente así) los objetivos de la calidad de vida y de las expectativas personales; así como las decisiones personales en materia de valores éticos, morales, culturales, sociales, filosóficos e incluso religiosos ${ }^{115}$.

El Legislador, a tal propósito, hubiese podido también reconocer expressis verbis la posibilidad de expresar cuáles son los valores personales del paciente a tener en consideración en la contextualización de las DAT, encontrando en éstos una ayuda para conocer sus orientaciones con el objetivo de adoptar las decisiones clínicas y operativas más cercanas a la voluntad del declarante. Tal contenido (manifestaciones sobre sus creencias políticas, religiosas, relacionales, etc.) hubiese sido dirigido no tanto al médico, que claramente no posee las competencias interpretativas de las vivencias de un extraño, sino más bien al representante eventualmente designado, con el objeto de que éste se configure como un interlocutor válido del médico y del equipo sanitario para «orientarsi anche in situazioni e per trattamenti non specificamente previsti» ${ }^{116}$.

Esta previsión hubiese sido de gran utilidad por haber brindado la posibilidad de superar una previsión sobre la cual no es posible no detenerse alguna incerteza. El art. 4, ap. 1, decreta que toda persona mayor de edad y capaz de entender y de querer, en previsión de una eventual futura incapacidad de autodeterminarse puede, a través de las DAT, expresar su propia voluntad en materia de tratamientos sanitarios pero lo puede hacer «dopo avere acquisito adeguate informazioni mediche sulle conseguenze delle sue scelte».

La incerteza deriva del hecho que no se especifica en ninguna manera el modo de corroborar si la adquisición de la información se ha realizado ni tampoco que el proceso se haya cumplido adecuadamente. Las decisiones (sobre todo) sobre el fin de vida, que son predominantemente de naturaleza moral ${ }^{117}$, a menudo prescinden de un conocimiento exacto de las consecuencias sobre la salud, siendo éstas conocidas en modo general ${ }^{118}$. Generalidad que se expresa a través de fórmulas vagas - pero no por eso menos significativas - que dan forma a la expresión de las propias elecciones: «se mi troverò in una situazione nella quale non sia in grado di esprimermi personalmente sulle cure e sul trattamento della mia salute a causa di una malattia che mi renda dipendente dagli altri in maniera irreversibile e mi impedisca di esprimere la mia volontà chiara ed inequivoca di non vivere in tali circostanze, le mie disposizioni sono

\footnotetext{
115 Tal como es permitido, en cambio, por algunas legislaciones autonómicas españolas. Sobre tal punto, si se quiere, se remite a ADAMO, U., "Sulla disciplina giuridica delle instrucciones previas”, cit., p. 20.

${ }^{116}$ CASONATO, C., “A proposito del ddl sul testamento biologico”, cit., p. 1.

117 CASONATO, C., "Le direttive anticipate”, cit., 5.

118 «Se si ammette il diritto di rifiutare anche le cure salvifiche, non è di alcuna importanza, per chi desidera l'interruzione del trattamento, sapere quali sono i rischi che ciò comporta, oppure conoscere il tipo di alimentazione artificiale a cui sarà sottoposto in caso di coma. L'informazione (sul tipo di cura) non è funzionale alla decisione da prendere, perlomeno in tutti quei casi in cui la direttiva mira, per l'appunto, al rifiuto della cura»: CRICENTI, G., I giudici e la bioetica. Casi e questioni, Carocci, Roma, 2017, p. 107.
} 
per l'interruzione dei trattamenti di sostegno vitale e conseguente ricorso alla sedazione palliativa profonda continua» ${ }^{119}$.

La decisión de proceder o no tras haber adquirido las adecuadas informaciones médicas queda confinada, por lo tanto, a la responsabilidad de quien decide depositar una DAT $^{120}$, sobre todo porque sólo las DAT claras (más allá de su vaguedad o de su meticulosidad) serán vinculantes. Como se deduce de esta afirmación, el modo en que serán escritas las DAT será determinante y, por lo tanto, dependerá de la capacidad del sujeto el saber ejercitar en el mejor modo un derecho reconocido cuyo ejercicio - al igual que para todos los derechos - requiere, luego de la reivindicación, una "correcta utilización". A tal fin, el derecho, para ser ejercitado en el mejor modo, deberá ser conocido y esta afirmación no es una petitio principii si se considera que en todos los países en los que es posible la activación de los instrumentos de protección de la voluntad expresada “ahora para entonces”, el recurso a tal instrumento es mínimo. Indagar sobre las motivaciones de la no utilización de las DAT (por falta de conocimiento o por precisa voluntad) no respecta a la ciencia jurídica sino que es tarea de la ciencia sociológica, incluso si entre ellas existe almenos una que comprende una razón jurídica, o sea, que la redacción de las DAT no es obligatoria ${ }^{121}$.

\section{LA SEDACIÓN PALIATIVA PROFUNDA CONTINUA $Y$ SU NATURALEZA APLICATIVA.}

La ley n. 217 del 2019 hace referencia también a la sedación paliativa en el siguiente modo «en presencia de sufrimientos refractarios a los tratamientos sanitarios, el médico puede recurrir a la sedación paliativa profunda continua en asociación a la terapia del dolor, con el consentimiento del paciente. El recurso a la sedación paliativa profunda continua o el rechazo de la misma deben ser justificados y anotados en la historia clínica y en el archivo sanitario electrónico» ${ }^{122}$.

Resulta significativo el empleo de la terminología «sedazione palliativa profonda continua» en vez de la más común (aunque confusa) expresión "sedación terminal” o incluso "eutanasia indirecta”.

El equívoco que generalmente se insinúa cuando se habla de terminalidad, de hecho, coincide con aquel tratamiento a través del cual se pretende poner fin a la vida del paciente, como si se estuviera en presencia de un acto eutanásico. La sedación, específicamente, aquella continua y profunda no tiene como finalidad la muerte del paciente sino el "control" del dolor «la somministrazione intenzionale di farmaci ipnotici, alla dose necessaria richiesta, [es empleada] per ridurre il livello di coscienza fino ad annullarla, allo scopo di alleviare o abolire la percezione di un sintomo, senza

\footnotetext{
${ }^{119}$ Éste puede ser un ejemplo de DAT de contenido genérico.

${ }^{120}$ Que posee una naturaleza unilateral y no bilateral, no pudiéndose imaginar ni siquiera quién será el médico que deberá aplicar las DAT. Ampliamente PIZZETTI, F.G., Alle frontiere della vita, cit., p. 189.

${ }^{121} \mathrm{Al}$ respecto, SimONCINI, A., y CARTER SNEAD, O., Persone incapaci e decisioni di fine vita (con uno sguardo oltreoceano), Quaderni costituzionali, n. 1/2010, p. 23.

${ }^{122}$ Art. 2, app. 2, última parte, y 3, de la l. n. 219/2017.
} 
controllo, refrattario, fisico e/o psichico, altrimenti intollerabile per il paziente, in condizione di malattia terminale inguaribile in prossimità della morte» ${ }^{123}$.

La finalidad de la sedación continua y profunda es obstinadamente diferente del acto eutanásico ya que la primera práctica tiene como objetivo la eliminación del dolor mientras la segunda, en cambio, con el dolor, también la vida (biológica). Considerando la definición dada, resulta evidente que el fin (en un proceso que es de fin de vida) es aquel de aliviar o eliminar el sufrimiento a través del control de los síntomas refractarios (o sea, aquellos síntomas que no pueden controlarse, a la luz del "fracaso" de la identificación de tratamientos eficaces y que no comprometen el estado de conciencia). Su propósito es el tratamiento del dolor y no la suministración de fármacos destinada a provocar la muerte inmediata.

El objetivo de aliviar el sufrimiento refractario del paciente en fase avanzada o terminal prevalece por sobre la circunstancia factual, por lo cual el empleo de este tratamiento sanitario puede (y no en manera cierta y automática) provocar como efecto la reducción del tiempo de vida (doctrina del así dicho “doble efecto”) ${ }^{124}$; el procurar la muerte al paciente no es el efecto deseado en la medida en que la sedación (eliminación del dolor) constituye un acto moralmente aceptable ${ }^{125}$; el efecto positivo coincide con un efecto intencional de parte del agente, mientras el negativo debe ser previsto y tolerado. El efecto no deseado no debe ser el medio para negar el efecto deseado; el efecto positivo debe ser proporcialmente mayor respecto al negativo ${ }^{126}$.

Es necesario acoger con entusiasmo la referencia que se hace a la sedación paliativa profunda continua al interno de una ley que pretende presentarse como orgánica respecto a la amplia temática del fin de vida. De hecho, ésta es la primera vez que en un texto de ley se hace referencia explícita a tal tratamiento paliativo aunque la redacción del dispuesto de ley no se encuentre entre los más felices dado que requiere al intérprete la capacidad de entender la alusión al empleo del tratamiento de sedación ilustrando algunos presupuestos que legitiman su adopción.

Efectivamente, según el art. 2, ap. 2, del texto denominado Terapia del dolor, prohibición de obstinación irrazonable en los tratamientos médicos y dignidad en la fase del fin de vida, se lee, en la primera parte, que «[n]ei casi di paziente con prognosi infausta a breve termine o di imminenza di morte [cursivas nuestras], il medico deve astenersi da ogni ostinazione irragionevole nella somministrazione delle cure e dal ricorso a trattamenti inutili o sproporzionati». En la parte final del artículo se prevé que «[i]n presenza di sofferenze refrattarie ai trattamenti sanitari, il medico può ricorrere alla sedazionepalliativa profonda continua in associazione con la terapia del dolore, con il consenso del paziente».

Además de subrayar la superficialidad del adjetivo irrazonable que acompaña al lema obstinación - no pudiéndose verificar una obstinación que no sea por sí misma

\footnotetext{
${ }^{123}$ Según la reciente definición brindada por el Comité Nacional de Bioética en el documento Sedazione palliativa profonda continua nell'imminenza della morte del pasado 29 de enero del 2016, p. 7.

124 CACACE, S., "La sedazione palliativa profonda e continua nell'imminenza della morte: le sette inquietudini del diritto", Rivista italiana di Medicina Legale, n. 2/2017, pp. 470 y ss.

${ }^{125}$ Y así es para todos, v. PizzetTI, F. G., “Ai confini delle cure: la sedazione palliativa (o terminale) tra diritto di non soffrire e diritto di morire”, en MACCHIA, P., (coord.), Ai confini delle cure. Terapia, alimentazione, testamento biologico. Profili clinici, giuridici, etici, Edizioni Scientifiche Italiane, Nápoles, 2012, p. 138.

${ }^{126}$ NERI, D., Filosofia morale. Manuale introduttivo, Guerini Scientifica, Milán, 2013, p. 50.
} 
irrazonable (hubiese sido más correcto aludir al concepto de "ecceso" o de "insistencia" irrazonable) - se precisa que los dos períodos se encuentran divididos por un punto fijo. Según una interpretación meramente formal, parecería que el presupuesto de facto del pronóstico fatal a breve término o de muerte inminente en que se deberán encontrar los pacientes sea un requisito sólo para la interrupción y/o no inicio de la suministración de tratamientos que resulten ser frutos de una obstinación irrazonable y de tratamientos inútiles o desproporcionados (el llamado “encarnizamiento terapéutico”). Según esta interpretación, el hecho de recurrir a la sedación sería una plena opción del médico sólo en presencia de un sufrimiento refractario de cualquier tipo a los tratamientos sanitarios (como podría ser, por ejemplo, una importante cefalea), más allá de un pronóstico mortal de fin de vida.

El hecho que dicha interpretación pueda ser rechazada a favor de aquella que encuentra el diagnóstico fatal a breve término o la inminencia de muerte como presupuesto eficaz (también) para recurrir en modo legítimo a la sedación paliativa profunda continua, es validado por una doble interpretación lógico-sistemática. En primer lugar, la segunda parte del apartado citado encuentra fundamento en la primera parte, en la cual se hace referencia al pronóstico que, en caso de verificarse, consiente la intervención, rectius las intervenciones. En segundo lugar, si se hace referencia a la ley n. 38 del 15 de marzo del 2010 (Disposiciones para garantizar el acceso a las curas paliativas y a la terapia del dolor) ${ }^{127} \mathrm{y}$, más precisamente, a su segundo artículo, donde se especifica que los tratamientos paliativos - los cuales incluyen la sedación profunda continua, dado que ésta no se configura como un tratamiento del dolor ${ }^{128}$ - están representados por el conjunto de intervenciones terapéuticas, diagnósticas y asistenciales «finalizzati alla cura attiva e totale dei pazienti la cui malattia di base, caratterizzata da un'inarrestabile evoluzione e da una prognosi infausta, non risponde più a trattamenti specifici» ${ }^{129}$.

Sólo el contexto de fin de vida legitima tales tratamientos.

\section{REDACCIÓN DE LAS DISPOSICIONES ANTICIPADAS DE TRATAMIENTO}

Visto que las DAT pueden ser redactadas en cualquier momento, es preciso señalar un vacío al interno de la ley: no se prevé, de hecho, ni la obligación de inserirlas en el registro telemático ni se ha instituido un archivo único nacional informático ${ }^{130}$. Solo en

\footnotetext{
${ }^{127}$ Véase para todos, PEzzinI, B., "Diritto costituzionale alla salute, trattamento sanitario, cure palliative: spunti di riflessione terapeutica", en STRADELla, E., (coord.), Diritto alla salute e alla "vita buona" nel confine tra il vivere e il morire. Riflessioni interdisciplinari, Pisa, 2011, pp. 169 y ss.

${ }^{128}$ Que representa «[l]'insieme di interventi diagnostici e terapeutici volti a individuare e applicare alle forme morbose croniche idonee e appropriate terapie farmacologiche, chirurgiche, strumentali, psicologiche e riabilitative, tra loro variamente integrate, allo scopo di elaborare idonei percorsi diagnostico-terapeutici per la soppressione e il controllo del dolore».

${ }^{129}$ Art. 2 de la l. n. 38 del 2010.

${ }^{130}$ Art. 4, ap. 7, de la l. n. 219/2017: «[l]e regioni che adottano modalità telematiche di gestione della cartella clinica o il fascicolo sanitario elettronico o altre modalità informatiche di gestione dei dati del singolo iscritto al Servizio sanitario nazionale possono, con proprio atto, regolamentare la raccolta di copia delle DAT, compresa l'indicazione del fiduciario, e il loro inserimento nella banca dati, lasciando
} 
este modo se aseguraría la certera posibilidad de acceder siempre y en cualquier lugar a la documentación necesaria (especialmente en las situaciones de emergencia-urgencia) y de poder hacerlo en modo seguro e inmediato. Por lo tanto, si bien se pueden prever diversas formas de "disposición”, lo importante es que las normativas se elaboren con una cierta atención en lo que respecta los procedimientos de localización de documentos en base a los más modernos y confiables criterios de archivo. Sólo en este modo, por otro lado, se efectivizará el derecho a decidir sobre los tratamientos que se reciben durante una fase de inconciencia.

La rapidez en la recolección de la información está relacionada con la quaestio de la vinculación de las DAT a las situaciones de emergencia. La tesis es que incluso en condiciones de urgencia o cuando el sujeto se encuentre en inmediato peligro de vida, las DAT deben ser aplicadas, siempre que in dubio pro vita ${ }^{131}$. En caso que las instrucciones presentes en las DAT no fueran disponibles, es cierto que el médico debe ejercitar la propia profesión según ciencia y conciencia. Es justamente la existencia de la duda (y por lo tanto la falta de una certeza escrita) que debe llevar a considerar como operante el denominado "principio de precaución” que es el único principio que no cierra la posibilidad de poder cambiar idea. Y, de hecho, se reserva la posibilidad de continuar en una dirección contraria en la medida en que al sujeto interesado - siempre y cuando haya salido de la situación de emergencia y, una vez recuperada la conciencia y la capacidad, pueda externar la propia voluntad consciente, o sea, siempre y cuando las DAT hayan sido objeto de la atención del médico - se le puedan suspender los tratamientos sanitarios iniciados (pero no concluidos) cuando éste no era capaz de manifestar su propia voluntad consciente. Nos encontramos en presencia de lo que podría definirse como “re-expansión” de las DAT.

Para resolver en modo positivo las soluciones dictadas por la urgencia del deber proveer $^{132}$ es, por lo tanto, más que oportuno tener las DAT a la distancia de un clic y, con éstas, la autorización para iniciar o no un preciso tratamiento sanitario.

comunque al firmatario la libertà di scegliere se darne copia o indicare dove esse siano reperibili». Nótese el Dictamen (favorable con condiciones) de la Comisión Parlamentaria de Cuestiones Regionales - del 28 de junio del 2017 - que entró en juego durante la examinación de la ley por parte de la Comisión de Higiene y Salud. La comisión reclamaba la sentencia n. 262/2017 de la Corte constitucional como soporte a su propia resolución, con la cual se declaraba la inconstitucionalidad de la ley de la Región Friuli Venecia Julia que instituía el Registro de las DAT, argumentando que la legislación atributiva de relevancia pública por contener manifestaciones de voluntad que conciernen la libertad de tratamiento «necessita di uniformità di trattamento sul territorio nazionale, per ragioni imperative di eguaglianza, ratio ultima della riserva allo Stato della competenza legislativa esclusiva in materia di "ordinamento civile”, disposta dalla Costituzione». La Comisión, entonces, plantea las siguientes condiciones para un dictamen favorable del proyecto de ley examinado: «all'articolo 4, comma 6, sia prevista una disciplina uniforme a livello nazionale sulle modalità con cui gli enti territoriali sono chiamati a prendere in carico le DAT redatte per scrittura privata non autenticata; 2) all'articolo 4, comma 7, sia prevista una disciplina uniforme a livello nazionale della banca dati cui esso fa riferimento, per la quale appare necessario un coordinamento a livello nazionale».

${ }^{131}$ GARGANI, A., "Jus imperfectum? L'esercizio del diritto di rifiutare le cure tra esigenze di garanzia e prospettive di riforma”, Rivista italiana di Medicina Legale, n. 2/2014, p. 516; RUGGERI, A., Le dichiarazioni di fine vita, cit., 11; PIzzetTI, F. G., Alle frontiere della vita, cit., pp. 160 y ss.; GIUNTA, F., "Il morire tra bioetica e diritto penale”, Politica del diritto, n. 4/2003, p. 569.

${ }^{132}$ No obstante el hecho que la singularidad de la situación de emergencia no siempre permite la realización de una previsión atenta y precisa de un tratamiento. La consecuencia de dicha circunstancia sería (dependiendo de cada caso, naturalmente) la dificultad de interpretar las directivas presentes en las 
Si bien, como se ha afirmado, al aparato normativo le falta la previsión de la institución de un registro único nacional, remitiendo así la "posibilidad" a las regiones de establecer adecuados registros regionales; dicha laguna ${ }^{133}$, de todos modos, ha sido colmada por otro dispuesto normativo presente en la ley n. 205 del 27 de diciembre del 2017 (Ley de balance para el año 2018), con el cual se instituye, acompañado por un presupuesto de dos millones de euro, un banco de datos de nivel nacional destinado a registrar las disposiciones anticipadas de tratamiento ${ }^{134}$.

Antes de cerrar esta discusión, es necesario afrontar otra cuestión de la que todavía no se ha hablado y que no es de poca importancia, sino que todo lo contrario. Se recuerda que cuando fue comentado el art. 4, ap. 5, de la l. n. 219 del 2017 se señaló que el médico tiene el deber de respetar las DAT pero puede desatenderlas en caso de que éstas fueran claramente incoherentes. Para comprender la ratio de la previsión normativa y definir su entidad, es necesario volver a la quaestio sobre cómo deben escribirse las DAT.

Lejos de debilitar la entidad de las Disposiciones, el médico deberá desentenderlas cuando, a la luz de las mismas, comprenda (incluso con la ayuda del fiduciario) que el contenido de las DAT no expresa en modo adecuado la voluntad del subscriptor. Dicho en otro modo, si el declarante se limita a expresar que no quiere "ser entubado" o "ser reanimado", esto (muy probablemente) significa que no desea vivir bajo una condición de falta de mejoría de la propia condición de vida (restitutio ad integrum). Pero con esto no se tiene en cuenta de que algunas condiciones clínicas (piénsese a las maniobras de reanimación de emergencia que requieren un tratamiento de suporte a las condiciones vitales post traumáticas que han determinado, por ejemplo, un shock hemorrágico) la intubación puede representar un tratamiento que permite al paciente de poder recuperar "plenamente" de su propia condición clínica pre-patológica. En estos casos, el contenido de las DAT se manifiesta in re ipsa visiblemente incoherente.

Pero, ¿cómo comprender en modo correcto la finalidad del paciente, es decir, su voluntad? Justamente, a partir de lo que está escrito en las DAT y con la ayuda del fiduciario. En las disposiciones, como se ha visto en el ejemplo más arriba, no es necesario indicar en modo genérico un tratamiento que no se desea recibir, sino que es necesario que el sujeto ejercite su libertad en modo consciente y bien informado.

DAT, incluso porque el médico podría no estar seguro (por ej.) de las posibilidades concretas de recuperación o de la incidencia real de la enfermedad en las condiciones consideradas como no deseadas por el paciente. En tal sentido - y concuerdo - PIZZETTI, F.G., Alle frontiere della vita, cit., 162 y s.; FIORI, A., “Informazione e consenso all'atto medico", Il Comitato Nazionale per la Bioetica: 1990-2005. Quindici anni di impegno, Roma, 2006, p. 276.

${ }^{133}$ De un texto de ley que (al momento) aún no había sido promulgado.

${ }^{134}$ Según el art. 1, ap. 418, de la l. n. 205/2017: «[è] istituita presso il Ministero della salute una banca dati destinata alla registrazione delle disposizioni anticipate di trattamento (DAT) attraverso le quali ogni persona maggiorenne e capace di intendere e di volere, in previsione di un'eventuale futura incapacità di autodeterminarsi, può esprimere le proprie volontà in materia di trattamenti sanitari, nonché il consenso o il rifiuto rispetto ad accertamenti diagnostici o scelte terapeutiche e a singoli trattamenti sanitari. Per l'attuazione del presente apartado è autorizzata la spesa di 2 milioni di euro per l'anno 2018»; en el sig. ap., el 419, se indica que «[e]ntro centottanta giorni dalla data di entrata in vigore della presente legge, con decreto del Ministro della salute, previa intesa in sede di Conferenza permanente per i rapporti tra lo Stato, le regioni e le province autonome di Trento e di Bolzano e acquisito il parere del Garante per la protezione dei dati personali, sono stabilite le modalità di registrazione delle DAT presso la banca dati di cui al comma 418». 
Para tomar una decisión sobre el propio "futuro" es necesaria una documentación apropiada sobre las cuestiones que interesan a una persona que decide preocuparse por su propio estado de salud futuro. Debe saber, por lo tanto, que si la abstención de algunos tratamientos médicos (intubación y/o reanimación, para continuar con los ejemplos dados) no es acompañada por un determinado diagnóstico (con pronóstico mortal a breve término, de inminencia de muerte o de condición física y psíquica irrecuperables respecto a las condiciones anteriores al trauma patológico), esa no tiene ningún sentido, in primis médico-científico.

$\mathrm{Si}$, por lo tanto, se afirma que podrían presentarse como más razonables algunas expresiones como "deseo que no se inicien ni se continúen las intervenciones si el resultado de éstas fuera la prolongación de la fase terminal de mi existencia y si esta prolongación no consintiera ninguna posibilidad de recuperación, alargando así el sufrimiento" o "no deseo que se prolongue mi vida con medios artificiales como técnicas de soporte vital, fluidos por vía endovenosa, medicamentos (incluso antibióticos) o alimentación artificial (sonda nasogástrica)” podría afirmarse que otras como "no quiero ser entubado" o "no deseo ser reanimado" podrían poseer un criterio menor.

Sólo en el segundo de los dos ejemplos, por lo tanto, la solicitud es «manifiestamente incongrua» respecto a la finalidad que el mismo paciente (muy probablemente) desea obtener, sobre todo desde el momento en que la intervención se "escribe" como indeseada, podría pensarse que ésta podría ser funcional al objetivo del paciente, o sea, el bienestar y el mejoramiento físico-psíquico.

La excesiva "sinteticidad" de la escritura no debería ser una característica de la redacción de las DAT, dado que son pocos y limitados los casos en los que la brevedad del contenido del documento puede tener sentido, como por ejemplo en el caso de la anotación “nada de sangre” para los Testigos de Jehová ${ }^{135}$, lo que constituye el contenido de las DAT una excepción (no se acepta el tratamiento) a la regla (no se acepta el tratamiento por las consecuencias que puede causar sobre el cuerpo y la vida biográfica).

La correcta escritura de las disposiciones afecta también a otra figura jurídica en cuestión, es decir, la del fiduciario. La falta de previsión en las DAT de los valores que han inspirado al subscriptor a decidir en un sentido en detrimento de otro sobre su propia salud, ha reducido notablemente el rayo de acción del fiduciario quien, en presencia de una DAT redactada en modo puntual, habrá aún menos posibilidades de relacionarse con el médico; por el contrario, las posibilidades de relacionarse con el médico aumentarían si en las DAT fuera expresa no tanto la voluntad de recibir o no un tratamiento sino más bien la condición en la cual se desee o no recaer.

Continuando con el tema del modo en que se deben redactar las DAT, es preciso abordar el hecho empírico que coincide con la existencia de una gran variedad de documentos pre-impresos y puestos a disposición por entes públicos o por asociaciones privadas que responden a la exigencia de ayudar a la persona que quiera realizar una Disposición - y que, tal vez, no posea ninguna cultura médica - con el objetivo de indicar

${ }^{135}$ Es preciso aclarar que rechazan la transfusión de sangre en cualquier circunstancia, incluso en una situación de peligro de vida "superable” con dicha transfusión. 
detalladamente su propia voluntad futura, en modo que éstas resulten claras también para el sujeto al que se dirigen, o sea, in primis, al médico.

La preparación de formularios pre-impresos - es bueno recordarlo - no vincula en ningún modo al declarante, a quien se le reconoce la posibilidad de redactar las propias voluntades futuras en el modo que considere mejor y en el modo que piense que sea más oportuno, expresándose en manera más ${ }^{136}$ o menos ${ }^{137}$ detallada; personalizando el formulario standard; limitando al máximo la posibilidad de que un tipo de lenguaje excesivamente técnico comprima la voluntad del paciente entrando en contraste con la salvaguardia del principio de autonomía ${ }^{138}$ o, al contrario, que la propia voluntad expresada en modo vago, genérico, abstracto resulte, en práctica, no reconocible y por lo tanto no vinculante.

\section{CONCLUSIONES}

La muerte ya no es más un momento, un acto: ésta se ha convertido en un proceso, un recorrido largo, hospitalizado, medicalizado, tecnologizado - y por este motivo puede convertirse en objeto de elecciones conscientes -, en una época en la cual la institucionalización de los sistemas de tratamiento ha desplazado a la persona moribunda "desde la casa al hospital", aun teniendo conciencia del hecho que, claramente, la medicina no puede eliminar la muerte pero sí puede dilatar temporalmente su acontecimiento.

Considerando la actual sociedad de múltiples valores, es posible afirmar que el modo en que se debería regular el tema del bio-derecho ${ }^{139}$ debería coincidir con el consentimiento y no con la obstaculización, lo cual debería llevarse a cabo a través de una normativa lo más liviana posible, id est, abierta al reconocimiento amplio del principio de autodeterminación, escapando al riesgo de una posible matriz ideológica y por lo tanto divisible ${ }^{140}$. Y la ley sobre la cual se ha discutido en el presente trabajo va en dicha dirección.

\footnotetext{
${ }^{136}$ El riesgo es que la previsión hecha - consentimiento o no consentimiento a un determinado tratamiento - no concuerde con la realidad, dando como resultado una previsión anacrónica.

${ }^{137}$ El riesgo es que se trate de una previsión mecánica y que no vaya más allá de lo ya previsto por la jurisprudencia, por la legislación e incluso por el también código deontológico. El ejemplo que puede hacerse sobre el "encarnizamiento terapéutico" no parece una posibilidad fuera de lugar.

${ }^{138}$ V. TRIPODINA, C., Il diritto nell'età della tecnica, cit., p. 109.

${ }^{139}$ Sobre tal punto, si se quiere, se remite a ADAMO, U., "La tecnica di riproduzione assistita in Spagna. Regolamentazione giuridica e giurisprudenza costituzionale”, Dpce-online, n. 1/2015, pp. 131 y ss.

${ }^{140}$ Una aclaración respecto al empleo del término "ideología": claramente, no se pretende negar que el Legislador pueda tender hacia una ideología de base teleológica (que, de todos modos, debe respetar siempre aquella constitucional). Lo que se pretende decir es que también las ideologías deben "parlamentalizarse", en el sentido que deben equilibrarse todos los principios y todos los derechos constitucionales. Partiendo del presupuesto que lo dicho anteriormente sea indudable, resulta más oportuno que tal equilibrio se logre cuando se reglamentan materias que tienen por objeto las libertades y la autodeterminación fundadas, a su vez, sobre valores autónomos (ideológicos). Se remite a las reflexiones de GrASSO, G., "Consenso informato, libertà di scelta e disponibilità del proprio corpo", Forum di Quaderni costituzionali, p. 60; RAMACCI, F., "Premesse alla revisione della legge penale sull’aiuto al suicidio”, Studi in memoria di Pietro Nuvolone, II, Milán, 1991, pp. 203 y ss.
} 
En este contexto, las disposiciones anticipadas de tratamiento, comprendidas en modo apropiado, podrían constituir no sólo un instrumento válido para la tutela de los derechos de los pacientes que han perdido la capacidad de obrar, sino también una sólida y válida ayuda para los médicos ${ }^{141}$, quienes ya no estarán solos - dado que sus acciones encontrarán respaldo en la voluntad expresada por el paciente - y que aceptarán de buen grado el no "intentar" cualquier tratamiento y no llevar a cabo exámenes diagnósticos o terapias según protocolos anónimos o rutinarios que, la mayor parte de las veces, contribuyen a delinear lo que se define como "medicina defensiva".

Para el médico que sigue las disposiciones debe resultar claro que está ejerciendo un deber que es de tipo legal antes que deontológico y que, por lo tanto, la no punibilidad de la conducta médica (que sería de todos modos implícita) ha encontrado una precisa y conveniente positivación ${ }^{142}$.

Solamente una norma de ley, por otro lado, responde al clamoroso debate activo desde hace un tiempo y que sólo recientemente ha producido un serio y “constructivo” diálogo en ámbito parlamentario, aunque si bien se haya limitado actualmente sólo a las DAT. Un debate (el parlamentario) condicionado por las continuas maniobras dirigidas a procrastinar los tiempos de aprobación, las cuales han reducido el tiempo a disposición y no han consentido la asunción concreta de propuestas enmendativas para la formulación de un texto sin "sombras".

Las críticas a la reciente legislación sobre las DAT no han sido omitidas o descuidadas; pero ahora, en fase de conclusión, es posible concordar que es mejor tener una ley que no tenerla por ser imperfecta. Es siempre posible intervenir sobre ella para mejorarla. Todas las leyes, de hecho, son siempre perfectibles (aunque algunas lo son más que otras). El resultado legislativo, en su generalidad, parece haberse inserido sin inconvenientes al interno del panorama normativo de referencia, incluso porque considera en modo serio la laicidad inclusiva, excluyendo la imposición de una unívoca interpretación de valores.

Una lectura general del texto de ley nos lleva a evaluar favorablemente la disciplina jurídica de las DAT en cuanto sus puntos de fuerza - también aquellos considerados a la luz de sus posibles sombras - permanecen tales y de no poca entidad.

En general, las disposiciones anticipadas pueden considerarse un instrumento oportuno y relevante del que es posible disponer con el fin de tutelar la propia autonomía in primis delante del médico. Dicho de otro modo, la posibilidad reconocida al sujeto de poder elegir por sí mismo sobre las decisiones que le conciernen y que le permiten ser "patrón de sí mismo" aún bajo un estado de falta de conciencia, sigue siendo el «mejor modo» ${ }^{143}$ de respetar y mantener la propia dignidad y autonomía. El motivo de esto es que tales documentos son redactados por la misma persona a quien serán dirigidos o no los eventuales tratamientos sanitarios, y tales decisiones, aún si fueran sido adoptadas "ahora para entonces”, son seguramente siempre más "válidas” respecto a aquellas tomadas por un sujeto extraño como podría ser un médico o un propio familiar.

${ }^{141}$ V. PICIOCCHI, C., Op. cit., p. 10.

${ }^{142}$ V. art. 1, ap. 6, de la l. n. 219/2017.

${ }^{143}$ V. MARCOS DEL CANO, A.Ma., "Las instrucciones previas: su regulación jurídica en España”, en Palomar Olmeda, A., y Cantero Martínez, y Larios Risco, D., y GonzÁlez García, L., y De MontAlVo JäÄSKElÄInEN, F., (coords.) Tratado de derecho sanitario, I, Navarra, 2013, p. 843. 
La voluntad expresada en las disposiciones, la cual es libre de toda constricción, provocará repercusiones (sólo) sobre el sujeto que la ha manifestado. Pero todavía hay más. Es necesario definir, de hecho, que las decisiones contenidas en las disposiciones tienen efectos no sólo "internas" sino que también efectos en el ámbito externo y relacional, en acepción psicológico-afectiva y jurídico-probatoria, o sea, éstas «contribuyen a disminuir el temor de los pacientes a que se produzcan situaciones indeseadas, mejoran la relación médico-paciente y facilitan al médico información sobre posibles problemas éticos con el enfermo a la vez que le proporcionan una seguridad respecto a denuncias futuras» ${ }^{144}$.

En conclusión, la correcta predisposición de las DAT puede reducir las problemáticas inherentes a su propia eficacia y, por lo tanto, a su propia efectividad, y el uso de las mismas puede representar un utilísimo instrumento para ampliar el habeas corpus de quien vive en la era tecnológica.

${ }^{144}$ Ibidem. Continúa el Autor citado: «por otra parte, suponen un gran alivio y ayuda para la familia del paciente, disminuyendo su inseguridad o su sentimiento de culpabilidad por no hacer todo lo posible, al tener la seguridad que lo que se está haciendo es lo que él o ella quería». 